\title{
Construction and validation of a prognostic signature using CNV-driven genes for hepatocellular carcinoma
}

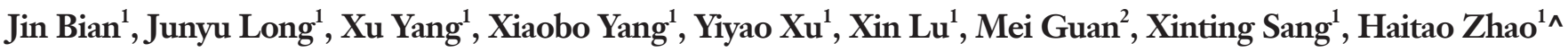 \\ ${ }^{1}$ Department of Liver Surgery, State Key Laboratory of Complex Severe and Rare Disease, Peking Union Medical College Hospital, Chinese \\ Academy of Medical Sciences and Peking Union Medical College (CAMS \& PUMC), Beijing, China; ${ }^{2}$ Department of Medical Oncology, Peking \\ Union Medical College Hospital, Chinese Academy of Medical Sciences and Peking Union Medical College (CAMS \& PUMC), Beijing, China \\ Contributions: (I) Conception and design: J Bian, J Long, M Guan, X Sang, H Zhao; (II) Administrative support: X Lu, X Sang, H Zhao; (III) \\ Provision of study materials or patients: J Bian, X Yang, X Yang, X Lu; (IV) Collection and assembly of data: J Bian, X Yang, Y Xu; (V) Data analysis \\ and interpretation: J Bian, J Long, M Guan; (VI) Manuscript writing: All authors; (VII) Final approval of manuscript: All authors. \\ Correspondence to: Mei Guan, MD. Department of Medical Oncology, Peking Union Medical College Hospital, Chinese Academy of Medical Sciences \\ and Peking Union Medical College (CAMS \& PUMC), 1 Shuaifuyuan, Wangfujing, Beijing 100730, China. Email: guanmei71@126.com; Xinting \\ Sang, MD. Department of Liver Surgery, Peking Union Medical College Hospital, Chinese Academy of Medical Sciences and Peking Union Medical \\ College (CAMS \& PUMC), 1 Shuaifuyuan, Wangfujing, Beijing 100730, China. Email: sangxt2010@163.com; Haitao Zhao, MD. Department \\ of Liver Surgery, Peking Union Medical College Hospital, Chinese Academy of Medical Sciences and Peking Union Medical College (CAMS \& \\ PUMC), 1 Shuaifuyuan, Wangfujing, Beijing 100730, China. Email: zhaoht@pumch.cn.
}

Background: Hepatocellular carcinoma (HCC) is one of the major causes of cancer-related deaths worldwide. Copy number variations (CNVs) affect the expression of genes and play critical roles in carcinogenesis. We aimed to identify specific CNV-driven genes and establish a prognostic model for HCC.

Methods: Integrative analysis of CNVs difference data and differentially expressed genes (DEGs) data from The Cancer Genome Atlas (TCGA) were conducted to identify critical CNV-driven genes for HCC. A risk model was constructed based on univariate Cox regression analysis, Least Absolute Shrinkage and Selection Operator (LASSO), and multivariate Cox regression analyses. The associations between CNV-driven genes signature and infiltrating immune cells were explored. The International Cancer Genome Consortium (ICGC) dataset was utilized to validate this model.

Results: After integrative analysis of CNVs and corresponding mRNA expression profiles, $568 \mathrm{CNV}$ driven genes were identified. Sixty-three CNV-driven genes were found to be markedly associated with overall survival (OS) after univariate Cox regression analysis. Finally, eight CNV-driven genes were screened to generate a prognostic risk model. Compared with low-risk group, the OS of patients in the high-risk group was significantly shorter in both the TCGA [hazard ratio (HR) $=6.14,95 \%$ confidence interval (CI): 2.72-13.86, $\mathrm{P}<0.001]$ and ICGC $(\mathrm{HR}=3.23,95 \% \mathrm{CI}$ : 1.17-8.92, $\mathrm{P}<0.001)$ datasets. Further analysis revealed the infiltrating neutrophils were positively correlated with risk score. Meanwhile, the high-risk group was associated with higher expression of immune checkpoint genes.

Conclusions: A novel signature based on CNV-driven genes was built to predict the survival of HCC patients and showed good performance. The results of our study may improve understanding of the mechanism that drives HCC, and provide an immunological perspective for individualized therapies.

Keywords: Copy number variation-driven genes (CNV-driven genes); hepatocellular carcinoma (HCC); prognosis; immune microenvironment

Submitted Oct 25, 2020. Accepted for publication Mar 10, 2021.

doi: 10.21037/atm-20-7101

View this article at: http://dx.doi.org/10.21037/atm-20-7101

$\wedge$ ORCID: 0000-0002-3444-8044.

(c) Annals of Translational Medicine. All rights reserved. 


\section{Introduction}

Hepatocellular carcinoma (HCC) is a lethal malignancy and accounts for approximately $85 \%$ to $90 \%$ of primary liver cancers $(1,2)$. Although targeted therapy and immunotherapy have emerged as potential therapies, curative therapies for HCC remain limited (3). Moreover, high post-operative recurrence rates and rare complete cures make it difficult for achieving long term survival. A study on natural history of HCC indicated that patients with advanced stage (Barcelona Clinic Liver Cancer Stage C) had a survival of only 3.4 months if untreated (4). HCC develops following a step-wise manner with abundant genetic and epigenetic molecular alterations (5). Therefore, it is crucial to achieve a better understanding of the underlying molecular mechanism that drives HCC occurrence and development. Exploring prediction model based on the factors that drive HCC can be useful for individualized therapy option and prognosis prediction for HCC patients.

As critical subclasses of somatic mutations, copy number variations (CNVs) refer to duplications or deletions of DNA segments, which are greater than $1 \mathrm{~kb}$ compared to a reference genome (6). CNVs account for the accumulation of genomic DNA aberrations, and play important role in cancer pathogenesis. Notably, CNVs can result in activation of oncogenes or inactivation of tumor suppressor genes, which drives cancer development $(7,8)$. Multiple CNVs have been reported to be implicated in the pathogenesis and prognosis of cancers including HCC (9-12). Frequent CNVs of subpopulations of cancer cells were reported to contribute to HCC heterogeneity, indicating a critical role of CNVs in HCC development and progression (13). However, most previous studies focused on CNVs or transcriptome alterations separately, and a comprehensive study of how CNVs drives HCC is still lacking. Combining analysis of CNVs and corresponding gene expression will promote more accurate identification of the specific cancer signatures for HCC. In this study, we used transcriptomic and CNVs profiles to identify CNV-driven genes and aimed to construct a prognostic model for HCC. Our research may contribute to better understanding of the underlying mechanisms, and provide novel therapeutic targets for HCC treatment. We present the following article in accordance with the TRIPOD reporting checklist (available at http://dx.doi. org/10.21037/atm-20-7101).

\section{Methods}

\section{Data collection}

Gene expression profiles (374 tumor samples and 50 normal samples) and DNA CNVs data (379 HCC samples and 389 nontumor samples) of HCC patients were obtained from The Cancer Genome Atlas (TCGA) (https://portal.gdc. cancer.gov/, up to November 1, 2019). The corresponding clinical parameters were also obtained. HCC RNAsequencing data were analyzed using the Illumina HiSeq 2000 RNA Sequencing platform, and CNVs data were analyzed with the Affymetrix SNP 6.0 platform. For validation cohort, RNA-sequencing profiles of $232 \mathrm{HCC}$ patients with survival time and status were downloaded from the International Cancer Genome Consortium (ICGC) (https://dcc.icgc.org/, up to April 3, 2019). All analyses were performed according to relevant regulations and guidelines. The study was conducted in accordance with the Declaration of Helsinki (as revised in 2013).

\section{Identification of differentially expressed genes (DEGs) between tumor and normal tissues}

To identify genes critical for HCC development, we used the "edgeR" R package to select DEGs between tumor and nontumor samples from TCGA (14). The $1 \log 2$ (fold change $[\mathrm{FC}]) \mid>2$ and false discovery rate $(\mathrm{FDR})<0.01$ were used as cutoff value for screening DEGs.

\section{Integrative analysis of gene expression and DNA CNVs}

Genes in CNV regions were annotated using Genome Research Consortium Human build 38 (GRCh38) as reference genome. The copy variation ratios of the genes both in normal and tumor samples were calculated and the gene-CNV matrix was constructed for Chi-square test. CNVs alteration rates between normal and tumor samples were then compared using Chi-square test, and CNVs data with adjusted $\mathrm{P}$ values less than 0.05 were chosen for next analysis. Then the CNVs data and DEGs data of the same sample were merged to construct a matrix. By using Kolmogorov-Smirnov test, those genes showing the same tendency both in CNVs and differential gene expression were selected as CNV-driven genes. Moreover, the differential expression of $\mathrm{CNV}$-driven genes between tumor and normal samples was compared by utilizing the Wilcoxon rank-sum test method. 


\section{Development and validating the risk prognostic model}

Prognostic CNV-driven genes were screened to construct a prognostic prediction model for the TCGA set. We employed univariate Cox proportional-hazards regression analyses to evaluate the associations between $\mathrm{CNV}$-driven DEGs and prognosis. Genes with a $\mathrm{P}<0.0001$ in univariate Cox regression analysis were selected for subsequent analysis. Least Absolute Shrinkage and Selection Operator (LASSO) regression analysis was employed to remove redundant variables and minimize overfitting (15). Then multivariate Cox proportional-hazards regression analysis was conducted to generate coefficients that were used as weights in the prognostic model. The prognostic prediction model including eight genes was built through a linear combination of mRNA expression level. The risk score $=$ $(0.06124 \times$ CDCA8 mRNA level $)+(0.05817 \times$ AKR1B15 mRNA level $)+(0.07457 \times$ EZH2 mRNA level $)+(0.02522$ $\times$ EPS8L 3 mRNA level $)+(0.05672 \times$ CBX2 mRNA level $)+$ $(0.02529 \times$ TRIM16L mRNA level $)+(0.11022 \times$ FLVCR 1 mRNA level $)+(0.11982 \times$ GPRIN1 mRNA level $)$. Based on the risk score model, patients were divided into two groups with high- or low-risks. The optimal risk score cutoff value was obtained using X-tile software (16). Kaplan-Meier (KM) and log-rank methods were used to compare the overall survival (OS) between the two subgroups. The receiver operating characteristic (ROC) curves were plotted, and the external validation of the predictive model was conducted in the ICGC database.

\section{Independence of risk score from other clinical features}

In TCGA group, 235 patients with both clinical information and corresponding gene expression were included in the analysis. In ICGC group, 232 patients were included for independence analysis. Univariate and multivariate analyses of OS were employed to evaluate whether the risk score was independent of other clinical features.

\section{Functional enrichment analysis and genome annotation}

To explore the underlying biological functions, we performed gene ontology (GO) and Kyoto encyclopedia of genes and genomes (KEGG) pathway enrichment analyses for CNV-driven genes. ClusterProfiler package (17) in R was used to plot the results.

\section{Association between CNV-driven genes prognostic signature and tumor-infiltrating immune cells}

Tumor Immune Estimation Resource (TIMER) is a comprehensive database for analyzing tumor-infiltrating immune cells (18). We utilized this database to estimate the abundance of major immune cell subpopulations in tumor immune microenvironment (CD4+ T cells, CD8+ T cells, $\mathrm{B}$ cells, macrophages, neutrophils, and dendritic cells) in HCC. The correlations between risk score and tumorinfiltrating immune cells were analyzed with Pearson test. Moreover, the expression levels of key immune checkpoint genes between high- and low-risk patients were compared by using Wilcoxon rank-sum test.

\section{Statistical analysis}

All the analyses were performed with $\mathrm{R}$ software (version 3.6.2). Unless otherwise specified, a $P$ value less than 0.05 was considered statistically significant.

\section{Results}

\section{DEGs in HCC}

After data was collected as described in Methods, 3,598 DEGs between tumor and nontumor samples were identified. Among these DEGs, 3,298 genes were upregulated and 300 genes were downregulated. These DEGs were used for further analysis.

\section{Identification of CNV-driven genes in HCC patients}

By applying Chi-square test, 16,644 HCC-related CNV genes were identified (adjusted $\mathrm{P}<0.05$ ). The distribution of HCC-related CNVs in the chromosomes is shown in Figure 1. Then CNV-driven genes were screened using Kolmogorov-Smirnov test. The Kolmogorov-Smirnov test identified $568 \mathrm{CNV}$-driven genes for HCC (Table S1). To illustrate the functional characteristics and biological effects of these $\mathrm{CNV}$-driven genes, GO and KEGG analyses were conducted (Figure 2A,B). Results showed CNV-driven genes were significantly enriched in categories associated with cell division and proliferation, such as "nuclear division", "chromosome, centromeric region", and "ligand-gated ion channel activity". These results indicate that the CNVdriven genes are involved in the dysregulation of tumor cell 
proliferation, and are critical in the molecular mechanisms of HCC development. Results from KEGG analysis showed that the top six signaling pathways were cell cycle, melanoma, p53 signaling pathway, mineral absorption, oocyte meiosis and gastric cancer. Most of these signaling

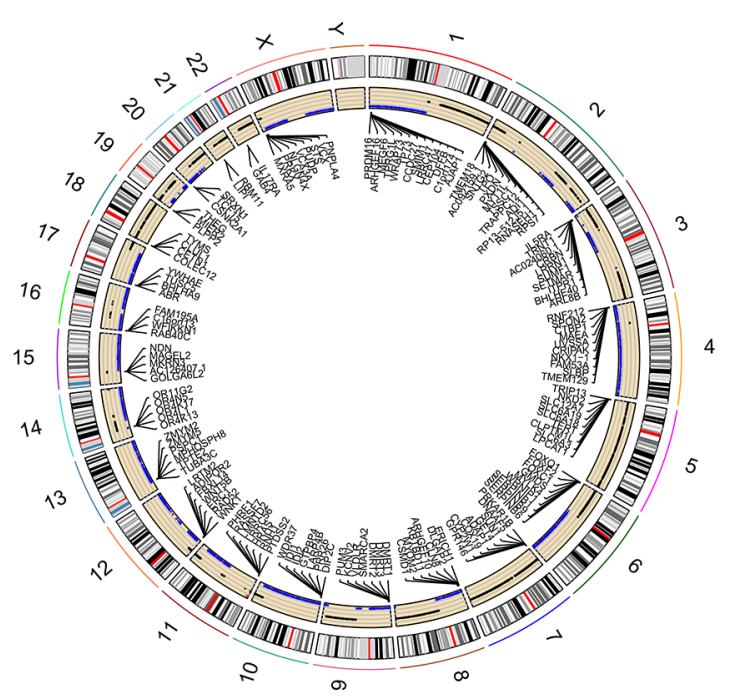

Figure 1 Distribution of HCC-related CNVs visualized by circos plot. The outside circle represents 24 chromosomes including sex chromosomes; the inside circle represents distribution of CNVs (the blue dots represent CNV deletions). HCC, hepatocellular carcinoma; $\mathrm{CNV}$, copy number variation. pathways are involved in tumor initiation and progression, indicating that the $\mathrm{CNV}$-driven genes are critical in the molecular mechanisms of HCC development.

\section{Screening of prognostic CNV-driven genes associated with survival}

Wilcoxon rank-sum test was used to analyze the difference of the $568 \mathrm{CNV}$-driven genes between tumor and nontumor tissues (FDR $<0.05$ and $|\log 2[\mathrm{FC}]|>1$ ), and 373 differentially expressed $\mathrm{CNV}$-driven genes were finally selected (Table S2). Of the $373 \mathrm{CNV}$-driven genes, 63 $\mathrm{CNV}$-driven genes were identified as potential prognostic biomarkers for OS after univariate analysis $(\mathrm{P}<0.0001$, Table S3).

\section{Generating and evaluating the HCC prognosis prediction model}

The 63 selected CNV-driven genes were analyzed by LASSO regression method. Eight genes appeared 800 times of a total of 1000 repetitions and were detected as prognostic genes for building risk score (Figure $3 A, B$ ). Then, using the coefficients from multivariate Cox regression, we built a model based on the eight CNVdriven genes (Table S4). Hazard ratios of all the eight $\mathrm{CNV}$-driven genes were greater than 1 , indicating these genes were associated with shorter OS of HCC patients. Based on the optimal cutoff value of 2.43 for risk score, the
A

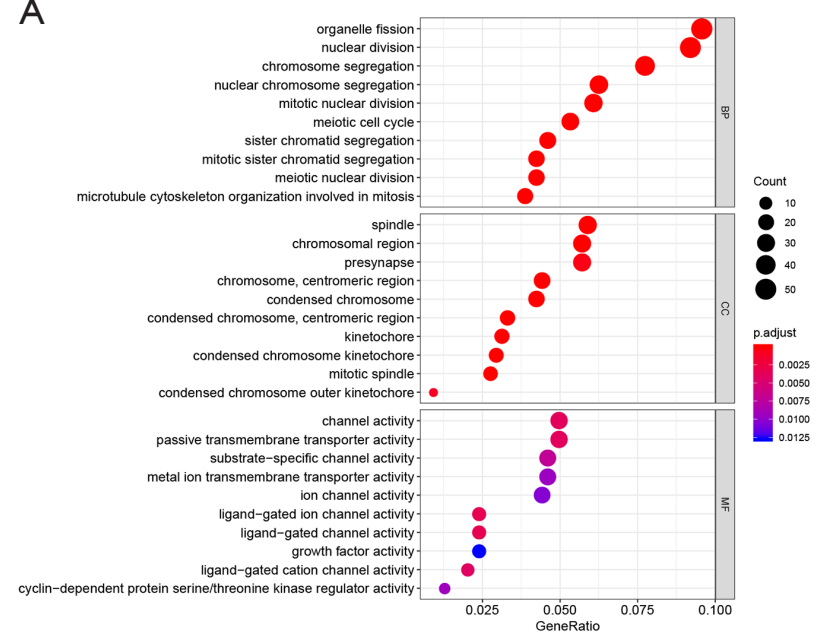

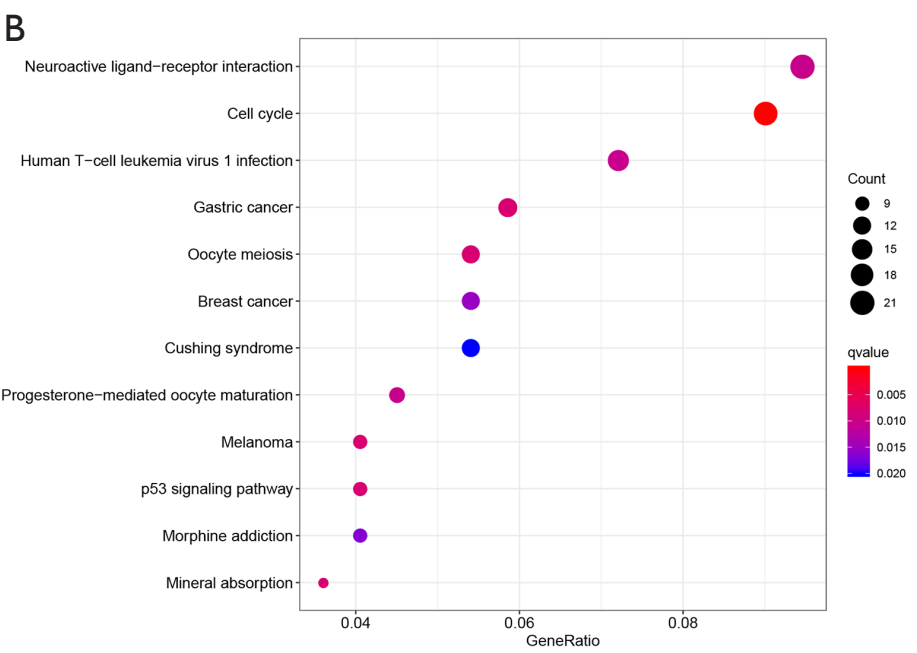

Figure 2 GO and KEGG enrichment for CNV-driven genes. (A) GO enrichment. (B) KEGG pathway enrichment. GO, gene ontology; KEGG, Kyoto encyclopedia of genes and genomes; CNV, copy number variation. 

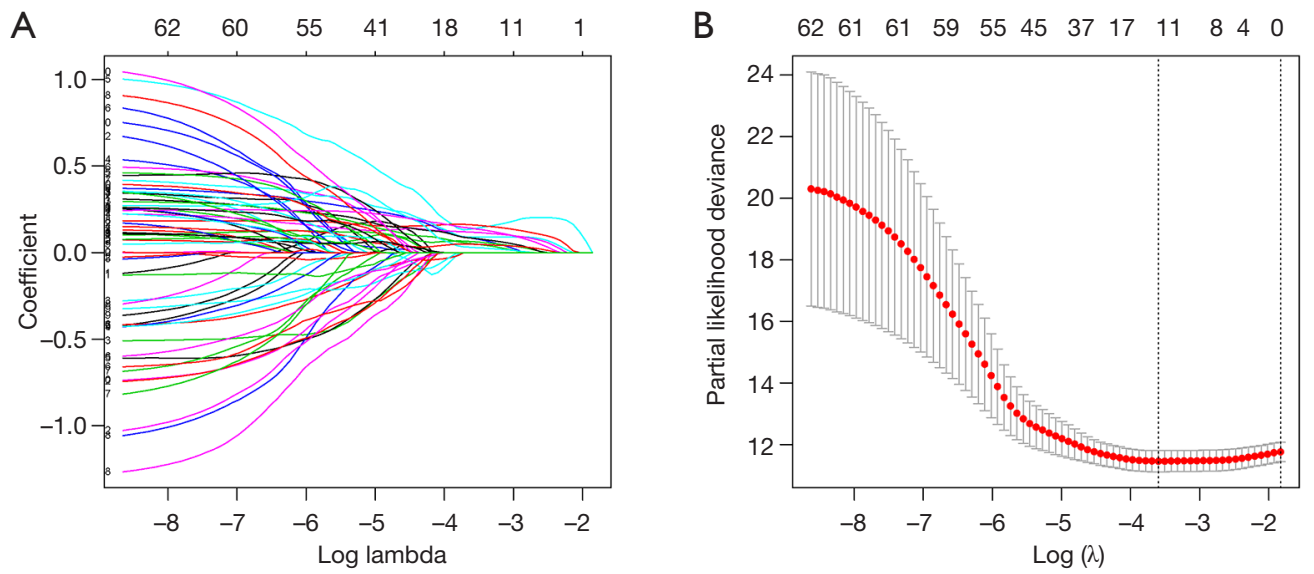

Figure 3 Selection of the prognostic CNV-driven genes for HCC patients by LASSO. (A) The LASSO coefficient changing profiles of 63 CNV-driven genes. (B) Determining the optimal lambda value in the LASSO by ten-fold cross-validation. Confidence intervals for each lambda was shown. CNV, copy number variation; HCC, hepatocellular carcinoma; LASSO, least absolute shrinkage and selector operation.

patients were grouped into two subgroups with high- and low-risks respectively. Patients with high-risk scores had significantly shorter OS (HR $=6.14,95 \%$ CI: $2.72-13.86$, $\mathrm{P}<0.001)$ than patients in low-risk group (Figure $4 A$ ). The risk score distributions and expression of $\mathrm{CNV}$-driven genes were plotted (Figure 4B,C,D). Expression levels for the eight $\mathrm{CNV}$-driven genes increased as risk scores, indicating these $\mathrm{CNV}$-driven genes were high risk factors for OS. The area under the ROC curve (AUC) curve for the 3-year OS was 0.704 (Figure S1A). The risk prognosis model was validated using external independent data from ICGC datasets. HCC patients in validating cohort were designated into high- and low-risk groups using the same risk score formula and cutoff obtained from the TCGA group. Compared to the low-risk group, high-risk group showed significantly poorer OS (HR $=3.23$, 95\% CI: $1.17-8.92, \mathrm{P}<0.001$ ) (Figure 4E). The risk score distribution, vital statuses of patients, and expression levels of CNV-driven genes were shown in Figure 4F,G,H. The AUC of the 3-year OS was 0.768 for HCC patient in ICGC dataset (Figure S1B).

\section{Independent of the prognostic model from other clinical features in TCGA and ICGC}

Univariate and multivariate Cox proportional-hazards model were used to determine whether the risk score prognostic model was independent of clinical and pathological parameters (Tables 1,2). Among 235 patients in TCGA datasets, univariate analyses indicated that $\mathrm{T}$ category (primary tumor), TNM stage, and risk score were significantly correlated with OS $(\mathrm{P}<0.001)$. Multivariate analysis showed that the $\mathrm{CNV}$-driven genes prognostic risk score was the only significant independent predictor for OS $(\mathrm{P}<0.001)$. Among 232 patients in ICGC, univariate analysis showed that risk score $(\mathrm{P}<0.001)$ and $T N M$ stage $(\mathrm{P}<0.001)$ were related with OS, and further multivariate analysis showed risk score was still a predictor for OS independent of TNM stage $(\mathrm{P}<0.001)$.

\section{Analysis of the tumor-infiltrating cells and immune genes with the $C N V$-driven risk signature}

Tumor-infiltrating cells play critical roles in tumor immune balance and associate with cancer development. To explore whether the $\mathrm{CNV}$-driven genes prognostic model was associated tumor-infiltrating cells, we analyzed the relationship between risk score and six immune cell subsets. Pearson correlation tests showed that the abundance of CD8+ T cells, dendritic cells, neutrophils and macrophages were positively correlated with risk scores $(\mathrm{P}<0.05$, Figure 5$)$. Of note, the Pearson correlation coefficient is largest in correlation between neutrophils and risk score, and the weakest correlation is observed between CD8+ T cells and risk score. There were no relations between risk score and $\mathrm{B}$ cells or CD4+ T cells. These results indicate that increased infiltrating neutrophils are associated with poorer survival and play a negative role in HCC immune balance. We further assessed the critical immune checkpoint genes expression between patients in high- and low-risk groups. As shown in Figure 6, high-risk cohort had higher expression 
A

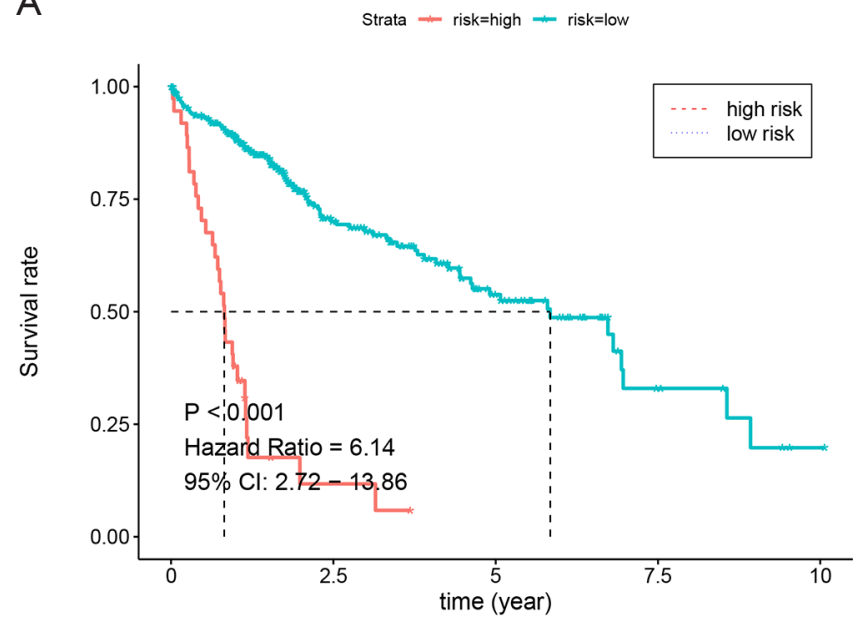

Number at risk

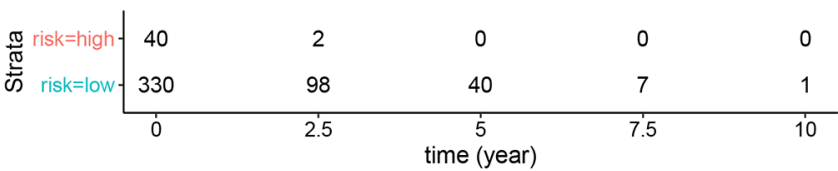

E

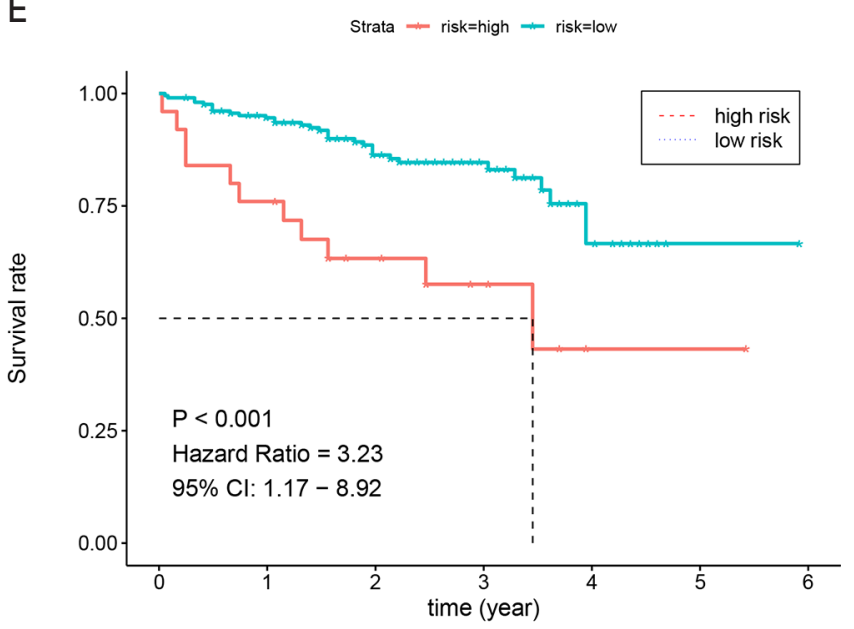

Number at risk

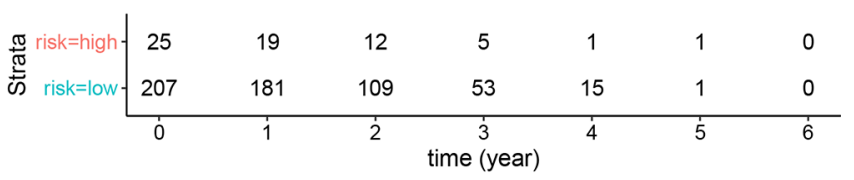

B

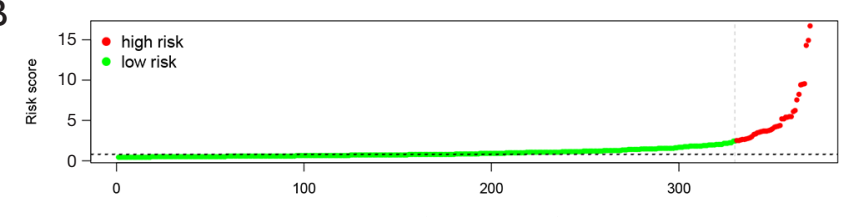

C

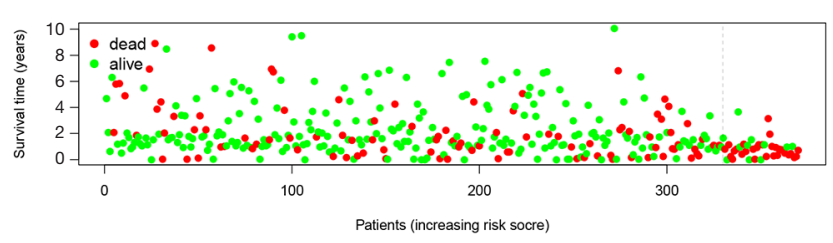

D

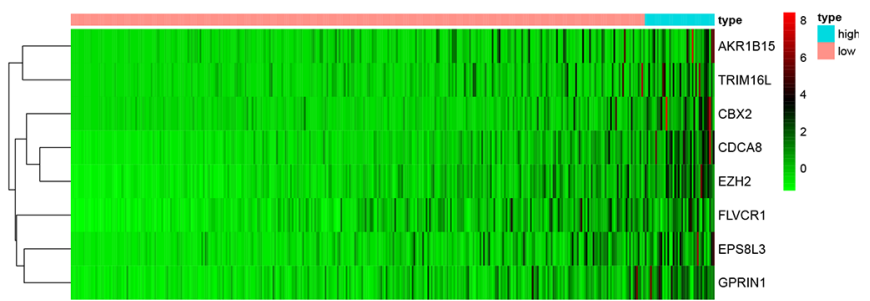

F

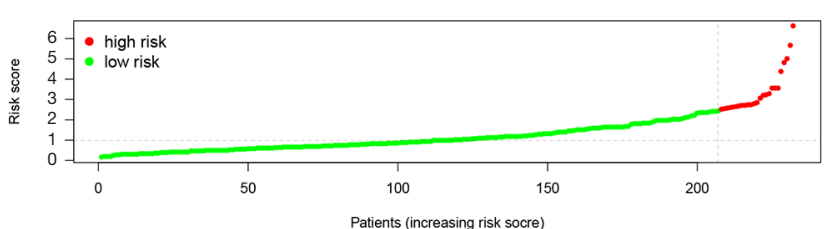

G

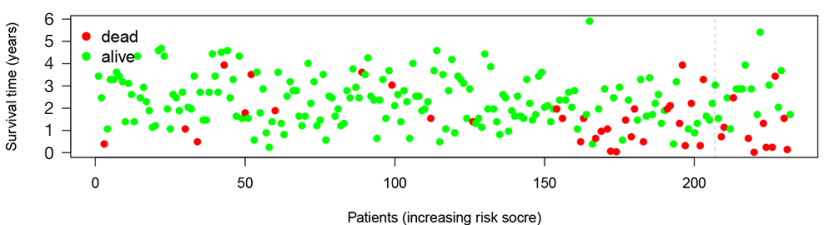

$\mathrm{H}$

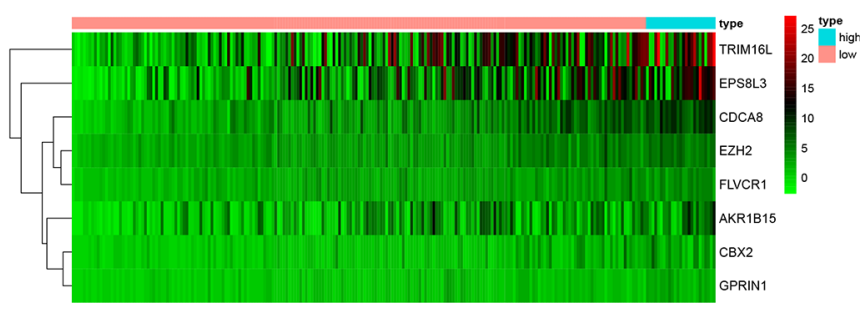

Figure 4 The Kaplan-Meier curves and the distribution of risk score, vital statuses, and CNV-driven genes expression. (A,E) K-M curves for the prognostic model in the TCGA set and ICGC set, respectively. (B,C,D) The distribution of risk score based on CNV-driven genes, the vital statuses of patients, and heatmap of the genes profiles in the TCGA set. (F,G,H) The risk score distribution, the vital statuses of patients, and heatmap of the gene profiles in the ICGC set. CNV, copy number variation; TCGA, The Cancer Genome Atlas; ICGC, International Cancer Genome Consortium. 
Table 1 Univariate and multivariate regression analyses for TCGA group

\begin{tabular}{|c|c|c|c|c|}
\hline Variables & \multicolumn{2}{|c|}{ Univariate analysis } & \multicolumn{2}{|c|}{ Multivariate analysis } \\
\hline Age & $1.005(0.987-1.023)$ & 0.591 & $1.008(0.989-1.028)$ & 0.421 \\
\hline Gender & $0.780(0.487-1.249)$ & 0.301 & $0.849(0.50-1.442)$ & 0.544 \\
\hline Grade & $1.017(0.746-1.387)$ & 0.914 & $1.077(0.767-1.514)$ & 0.668 \\
\hline $\mathrm{T}$ & $1.804(1.434-2.270)$ & 4.73E-07 & $0.843(0.302-2.357)$ & 0.746 \\
\hline M & $3.850(1.207-12.281)$ & 0.023 & $1.437(0.380-5.431)$ & 0.593 \\
\hline $\mathrm{N}$ & $2.022(0.494-8.276)$ & 0.328 & $0.838(0.092-7.622)$ & 0.876 \\
\hline Risk score & $1.260(1.180-1.347)$ & $6.57 \mathrm{E}-12$ & $1.242(1.137-1.357)$ & 1.404E-06 \\
\hline
\end{tabular}

TCGA, The Cancer Genome Atlas; HR, hazard ratio; Cl, confidence interval.

Table 2 Univariate and multivariate regression analyses for ICGC group

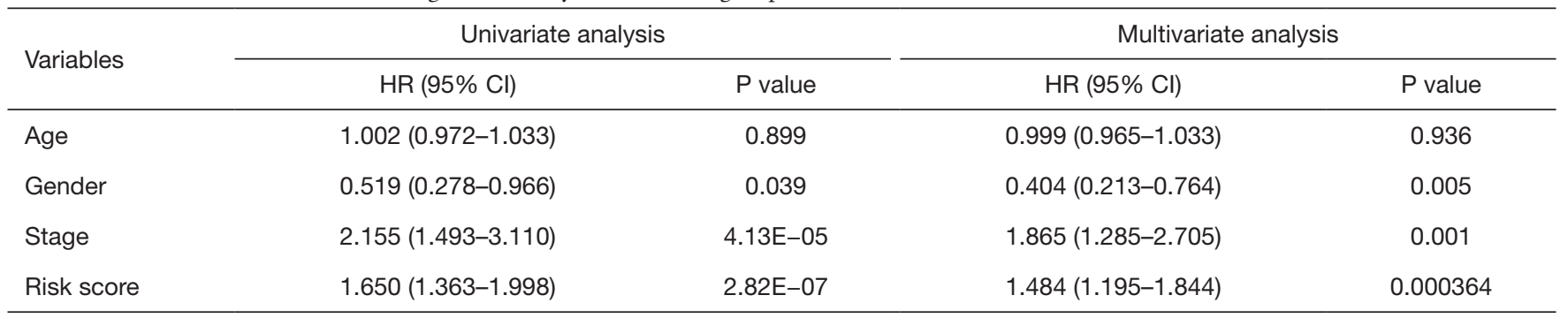

ICGC, International Cancer Genome Consortium; HR, hazard ratio; Cl, confidence interval.

levels of CTLA4, TIM-3, LAG3 and CD39 compared to those in the low-risk cohort $(\mathrm{P}<0.05)$. These results suggest that high-risk patients had higher immunoinhibitory gene expression, and may benefit from immunotherapy based on immune checkpoint inhibitors.

\section{Discussion}

HCC remains a major cause of cancer-related deaths in the world, causing one of the highest public health burdens $(19,20)$. Advancement in molecular analyses has facilitated deep understanding of the HCC mutation landscape and characteristics. Studies indicated that hepatocarcinogenesis was a multistep and multifactorial process caused by frequent aberrant gene alterations, including single nucleotide mutations and CNVs (21). Therefore, understanding the roles of CNVs in driving hepatocarcinogenesis is crucial for HCC prevention, treatment, and prognosis prediction.

Integrated genomic analysis can be an effective and essential method for identification of novel cancer driver genes. For instance, the widespread use of high-throughput sequencing has enabled more efficient and comprehensive analysis of $\mathrm{CNVs}$, and provides opportunities for revealing new genes underlying the development of HCC (22). CNVs in oncogenes and tumor suppressor genes are involved in HCC malignant proliferation and transformation. Previous studies on HCC showed that oncogenic driver genes CCND1 and FGF19 had increased amplifications of copy numbers (23), while tumor suppressor genes CDKN2A and CDKN2B contained high frequency of deletions (12). Analysis of recurrent CNVs can also help to identify potential novel biomarkers such as IRF2, which is unique to hepatitis virus B-related HCC (24).

In this work, we conducted an integrative analysis of CNVs and gene expression profiles aiming to identify $\mathrm{CNV}$-driven genes that associated HCC survival, and built a prognostic signature with $\mathrm{CNV}$-driven genes. In multivariate Cox proportional-hazards analysis, the prognostic risk score proved to be an independent predictor 

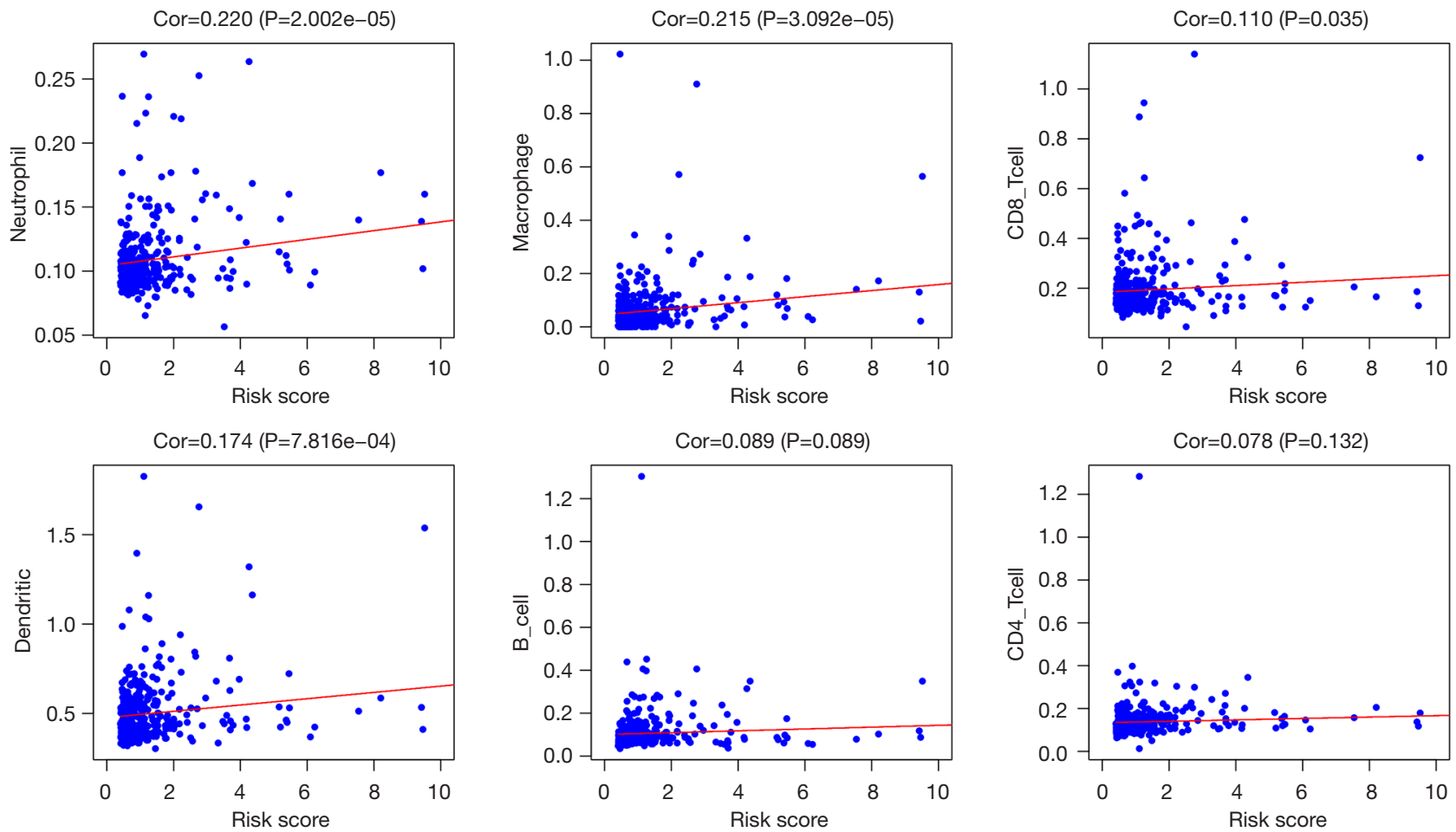

Figure 5 Relationships between the risk score and six immune cells for TCGA datasets. The Pearson correlation coefficients (Cor) are illustrated in each plot. TCGA, The Cancer Genome Atlas.
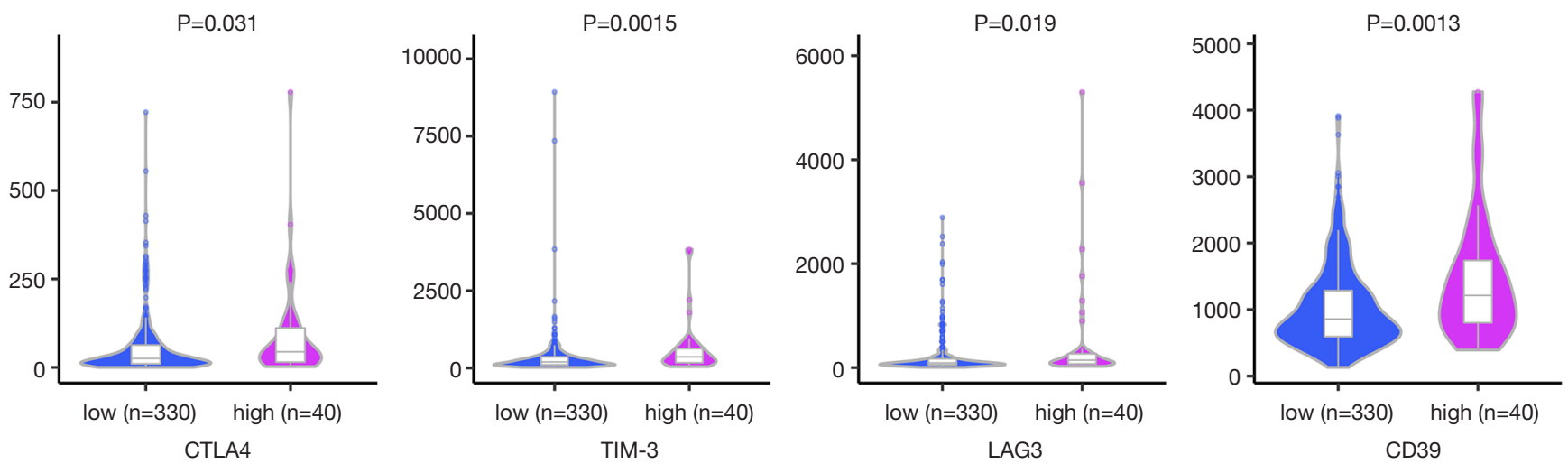

Figure 6 Comparison of immune checkpoints genes expression in the two risk subgroups.

for OS. Survival analysis showed the risk score prediction model had robust distinguishing ability, and might help to improve individualized prediction of OS in HCC patients.

Recent research results have highlighted the roles of tumor-infiltrating immune cells in HCC immune tolerance and survival prognosis $(25,26)$. Since CNVs can result in alterations of key genes responsible for cancer immune surveillance, we therefore investigated the associations between tumor-infiltrating immune cells, immune checkpoint genes, and the risk score. The results showed there was the strongest positive correlation between neutrophils and risk score, indicating increased infiltrating neutrophils were risk factor for survival. Previous studies have demonstrated that neutrophil activation could drive tumor progression and metastasis (27), and infiltrating neutrophils contributed to HCC progression, and 
associated with poor prognosis (28). These studies were consistent with our findings and implied that our risk prognostic signature was closely related with tumor immune microenvironment. Moreover, we explored the expression of immune checkpoint genes that had been proved critical in HCC. Based on the risk score, the gene expression of CTLA-4, TIM-3, LAG3, and CD39 were significantly higher in patients with high-risk. The high expression of immune checkpoint genes may be responsible for poorer survival of high-risk group. The prognostic signature can be utilized to identify high-risk populations who may benefit from cancer immunotherapy such as immune checkpoint inhibitors.

Our study has some limitations. Since the data is retrospective, the results need to be further confirmed in prospective studies. Moreover, the tumor-infiltrating immune cells and related genes expression remain to be further validated by experimental methods.

\section{Conclusions}

In summary, our study identified CNV-driven genes that related to HCC survival. A prognostic prediction model was established based on CNV-driven genes. Further analyses indicated that tumor-infiltrating immune cells and altered immune checkpoint genes might account for the model's prognostic capacity. These results contribute to the understanding of hepatocarcinogenesis from view of CNVs, and may improve outcome prediction for patients with HCC.

\section{Acknowledgments}

We thank Yu Lin (Statistician, Shenzhen Withsum Technology Limited) for assistance with the data interpretation.

Funding: This work was supported by the International Science and Technology Cooperation Projects, No. 2016YFE0107100; Capital Special Research Project for Health Development, No. 2014-2-4012; Beijing Natural Science Foundation, No. L172055 and No. 7192158; National Ten-thousand Talent Program, the Fundamental Research Funds for the Central Universities, No. 3332018032; and CAMS Innovation Fund for Medical Science (CIFMS), No. 2017-I2M-4-003 and No. 2018-I2M-3-001.

\section{Footnote}

Reporting Checklist: The authors have completed the
TRIPOD reporting checklist. Available at http://dx.doi. org/10.21037/atm-20-7101

Conflicts of Interest: All authors have completed the ICMJE uniform disclosure form (available at http://dx.doi. org/10.21037/atm-20-7101). The authors have no conflicts of interest to declare.

Etbical Statement: The authors are accountable for all aspects of the work in ensuring that questions related to the accuracy or integrity of any part of the work are appropriately investigated and resolved. The study was conducted in accordance with the Declaration of Helsinki (as revised in 2013). The data used in the current study are obtained from The Cancer Genome Atlas database (TCGA) and the International Cancer Genome Consortium (ICGC), which are open to the public under some guidelines. Therefore, it is confirmed that all written informed consent was achieved and no ethical approval was needed.

Open Access Statement: This is an Open Access article distributed in accordance with the Creative Commons Attribution-NonCommercial-NoDerivs 4.0 International License (CC BY-NC-ND 4.0), which permits the noncommercial replication and distribution of the article with the strict proviso that no changes or edits are made and the original work is properly cited (including links to both the formal publication through the relevant DOI and the license). See: https://creativecommons.org/licenses/by-nc-nd/4.0/.

\section{References}

1. Llovet JM, Zucman-Rossi J, Pikarsky E, et al. Hepatocellular carcinoma. Nat Rev Dis Primers 2016;2:16018.

2. Villanueva A. Hepatocellular Carcinoma. N Engl J Med 2019;380:1450-62.

3. Li ZL, Han J, Liu K, et al. Association of family history with long-term prognosis in patients undergoing liver resection of HBV-related hepatocellular carcinoma. Hepatobiliary Surg Nutr 2019;8:88-100.

4. Khalaf N, Ying J, Mittal S, et al. Natural History of Untreated Hepatocellular Carcinoma in a US Cohort and the Role of Cancer Surveillance. Clin Gastroenterol Hepatol 2017;15:273-81.e1.

5. Sia D, Villanueva A, Friedman SL, et al. Liver Cancer Cell of Origin, Molecular Class, and Effects on Patient Prognosis. Gastroenterology 2017;152:745-61. 
6. Sebat J, Lakshmi B, Troge J, et al. Large-scale copy number polymorphism in the human genome. Science 2004;305:525-8.

7. Nik-Zainal S, Davies H, Staaf J, et al. Landscape of somatic mutations in 560 breast cancer whole-genome sequences. Nature 2016;534:47-54.

8. Hoang PH, Dobbins SE, Cornish AJ, et al. Wholegenome sequencing of multiple myeloma reveals oncogenic pathways are targeted somatically through multiple mechanisms. Leukemia 2018;32:2459-70.

9. Liu W, Sun J, Li G, et al. Association of a germ-line copy number variation at $2 \mathrm{p} 24.3$ and risk for aggressive prostate cancer. Cancer Res 2009;69:2176-9.

10. Diskin SJ, Hou C, Glessner JT, et al. Copy number variation at 1q21.1 associated with neuroblastoma. Nature 2009;459:987-91.

11. Park RW, Kim TM, Kasif S, et al. Identification of rare germline copy number variations over-represented in five human cancer types. Mol Cancer 2015;14:25.

12. Wang K, Lim HY, Shi S, et al. Genomic landscape of copy number aberrations enables the identification of oncogenic drivers in hepatocellular carcinoma. Hepatology 2013;58:706-17.

13. Hou Y, Guo H, Cao C, et al. Single-cell triple omics sequencing reveals genetic, epigenetic, and transcriptomic heterogeneity in hepatocellular carcinomas. Cell Res 2016;26:304-19.

14. Robinson MD, McCarthy DJ, Smyth GK. edgeR: a Bioconductor package for differential expression analysis of digital gene expression data. Bioinformatics 2010;26:139-40.

15. Tibshirani R. The lasso method for variable selection in the Cox model. Stat Med 1997;16:385-95.

16. Camp RL, Dolled-Filhart M, Rimm DL. X-tile: a new bio-informatics tool for biomarker assessment and outcome-based cut-point optimization. Clin Cancer Res 2004;10:7252-9.

17. Yu G, Wang LG, Han Y, et al. clusterProfiler: an R package for comparing biological themes among gene clusters. Omics 2012;16:284-7.

Cite this article as: Bian J, Long J, Yang X, Yang X, Xu Y, Lu X, Guan M, Sang X, Zhao H. Construction and validation of a prognostic signature using CNV-driven genes for hepatocellular carcinoma. Ann Transl Med 2021;9(9):765. doi: 10.21037/atm-20-7101
18. Li T, Fan J, Wang B, et al. TIMER: A Web Server for Comprehensive Analysis of Tumor-Infiltrating Immune Cells. Cancer Res 2017;77:e108-10.

19. Bray F, Ferlay J, Soerjomataram I, et al. Global cancer statistics 2018: GLOBOCAN estimates of incidence and mortality worldwide for 36 cancers in 185 countries. CA Cancer J Clin 2018;68:394-424.

20. Xie DY, Ren ZG, Zhou J, et al. 2019 Chinese clinical guidelines for the management of hepatocellular carcinoma: updates and insights. Hepatobiliary Surg Nutr 2020;9:452-63.

21. Niu ZS, Niu XJ, Wang WH. Genetic alterations in hepatocellular carcinoma: An update. World J Gastroenterol 2016;22:9069-95.

22. Chen CF, Hsu EC, Lin KT, et al. Overlapping highresolution copy number alterations in cancer genomes identified putative cancer genes in hepatocellular carcinoma. Hepatology 2010;52:1690-701.

23. Sawey ET, Chanrion M, Cai C, et al. Identification of a therapeutic strategy targeting amplified FGF19 in liver cancer by Oncogenomic screening. Cancer Cell 2011;19:347-58.

24. Guichard C, Amaddeo G, Imbeaud S, et al. Integrated analysis of somatic mutations and focal copy-number changes identifies key genes and pathways in hepatocellular carcinoma. Nat Genet 2012;44:694-8.

25. Zheng C, Zheng L, Yoo JK, et al. Landscape of Infiltrating $\mathrm{T}$ Cells in Liver Cancer Revealed by Single-Cell Sequencing. Cell 2017;169:1342-56.e16.

26. Zhang Z, Ma L, Goswami S, et al. Landscape of infiltrating $B$ cells and their clinical significance in human hepatocellular carcinoma. Oncoimmunology 2019;8:e1571388.

27. Singel KL, Segal BH. Neutrophils in the tumor microenvironment: trying to heal the wound that cannot heal. Immunol Rev 2016;273:329-43.

28. Zhou SL, Yin D, Hu ZQ, et al. A Positive Feedback Loop Between Cancer Stem-Like Cells and Tumor-Associated Neutrophils Controls Hepatocellular Carcinoma Progression. Hepatology 2019;70:1214-30. 
A

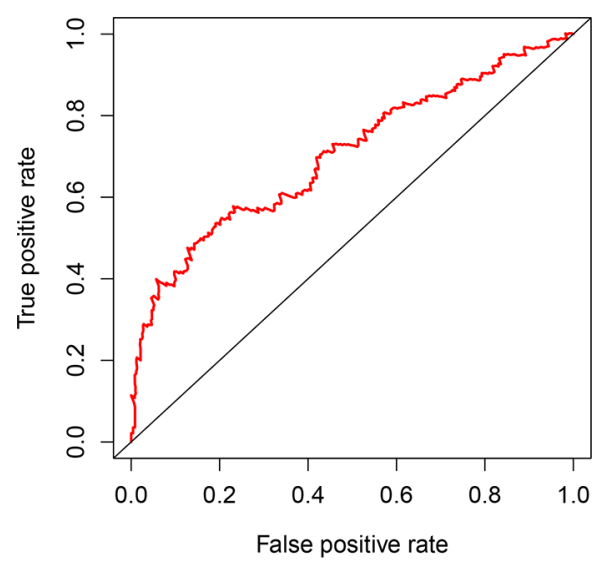

B

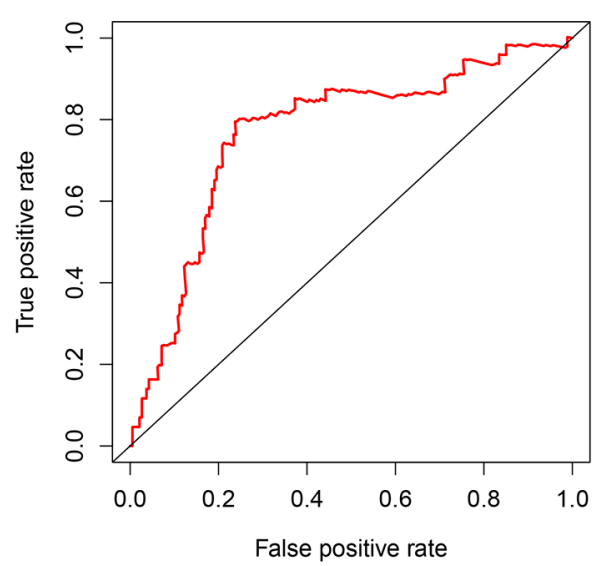

Figure S1 ROC curve of the risk prognostic model. (A) ROC of 3-year OS in TCGA set. (B) ROC of 3-year OS in ICGC set.

Table S1 Selection of 568 CNV-driven genes using K-S test

\begin{tabular}{|c|c|c|c|}
\hline geneName & pvalue & geneName & pvalue \\
\hline DSCC1 & $2.13 \mathrm{E}-23$ & CDC25A & 0.00395 \\
\hline PITPNM3 & $5.69 \mathrm{E}-17$ & MDFI & 0.003993 \\
\hline DCST2 & 8.93E-15 & OLFM3 & 0.004041 \\
\hline CENPL & 1.10E-13 & KBTBD11 & 0.004056 \\
\hline FLVCR1 & $1.23 \mathrm{E}-13$ & WDR76 & 0.004066 \\
\hline CAP2 & $1.79 \mathrm{E}-13$ & E2F2 & 0.0041 \\
\hline TK1 & 7.19E-12 & C19orf33 & 0.004205 \\
\hline ACTN2 & 8.03E-12 & SSUH2 & 0.004253 \\
\hline TRIP13 & $1.10 \mathrm{E}-11$ & OIP5 & 0.004384 \\
\hline DCST1 & $1.39 \mathrm{E}-11$ & FABP4 & 0.004394 \\
\hline GSTZ1 & $4.64 \mathrm{E}-11$ & LY6K & 0.004406 \\
\hline IQGAP3 & $9.71 \mathrm{E}-11$ & BEST4 & 0.004495 \\
\hline MSH5 & $9.86 \mathrm{E}-11$ & SHCBP1 & 0.004532 \\
\hline TRIM72 & $3.26 \mathrm{E}-10$ & DCX & 0.004536 \\
\hline GMNN & 8.36E-10 & MNS1 & 0.00472 \\
\hline SBSPON & 1.19E-09 & SLC6A9 & 0.00477 \\
\hline AURKA & 1.48E-09 & NAT2 & 0.004791 \\
\hline NUF2 & 2.29E-09 & GRIK4 & 0.004843 \\
\hline SAPCD1 & 2.30E-09 & PRAMEF8 & 0.005041 \\
\hline CENPW & 3.42E-09 & HPDL & 0.005155 \\
\hline
\end{tabular}

Table S1 (continued)
Table S1 (continued)

\begin{tabular}{|c|c|c|c|}
\hline geneName & pvalue & geneName & pvalue \\
\hline LHX4 & 4.31E-09 & DTL & 0.005272 \\
\hline SLC26A6 & 5.12E-09 & COL24A1 & 0.005405 \\
\hline E2F1 & 5.75E-09 & DLX1 & 0.005471 \\
\hline SLC6A2 & $1.65 \mathrm{E}-08$ & PLK4 & 0.005512 \\
\hline TPX2 & $2.67 \mathrm{E}-08$ & PRDM9 & 0.005513 \\
\hline STAR & 2.95E-08 & PIF1 & 0.005853 \\
\hline MT2A & 2.96E-08 & GJA10 & 0.0059 \\
\hline EPHA2 & 3.35E-08 & DMRT3 & 0.005936 \\
\hline KDM8 & 3.36E-08 & CXCL17 & 0.006061 \\
\hline EME1 & 6.71E-08 & PPFIA4 & 0.006076 \\
\hline MT1X & 7.26E-08 & TFAP2A & 0.006084 \\
\hline RCAN1 & 7.69E-08 & GRIN2B & 0.006138 \\
\hline TRIM45 & 7.79E-08 & SNCG & 0.006261 \\
\hline MTFR2 & 8.44E-08 & MCIDAS & 0.006303 \\
\hline CCNE1 & 8.45E-08 & NNMT & 0.006503 \\
\hline TCF19 & 9.96E-08 & HCRT & 0.006559 \\
\hline MFSD2A & $1.73 \mathrm{E}-07$ & CD109 & 0.006795 \\
\hline UBE2T & $1.82 \mathrm{E}-07$ & AKAP14 & 0.006841 \\
\hline CNNM1 & 2.19E-07 & RPRM & 0.006974 \\
\hline ADRA1A & 2.20E-07 & MAD2L1 & 0.006995 \\
\hline
\end{tabular}

Table S1 (continued) 
Table S1 (continued)

\begin{tabular}{|c|c|c|c|}
\hline geneName & pvalue & geneName & pvalue \\
\hline ACSM3 & $3.04 \mathrm{E}-07$ & OPRK1 & 0.00701 \\
\hline ARHGEF39 & $3.04 \mathrm{E}-07$ & ASB16 & 0.007061 \\
\hline NKD1 & $3.80 \mathrm{E}-07$ & SULT4A1 & 0.007136 \\
\hline CDKN2A & 3.99E-07 & PKMYT1 & 0.007136 \\
\hline TERT & 4.29E-07 & NEK2 & 0.007276 \\
\hline DNAJC6 & 7.76E-07 & SPP1 & 0.007557 \\
\hline EGR3 & 8.85E-07 & HIST2H4A & 0.007651 \\
\hline ECT2 & 9.35E-07 & TDGF1 & 0.007689 \\
\hline ZNF296 & $9.40 \mathrm{E}-07$ & TNFRSF19 & 0.007692 \\
\hline HP & 1.30E-06 & SERPINE1 & 0.007697 \\
\hline CAPN9 & $2.54 \mathrm{E}-06$ & CSRNP1 & 0.00781 \\
\hline ZNF648 & 2.69E-06 & GAGE12J & 0.007974 \\
\hline SLC2A5 & 2.86E-06 & IQCD & 0.007995 \\
\hline DPF1 & 3.70E-06 & POPDC3 & 0.008109 \\
\hline GLUL & $3.96 \mathrm{E}-06$ & NTF3 & 0.008207 \\
\hline GNAO1 & 4.16E-06 & HHIP & 0.008249 \\
\hline CLVS1 & 4.21E-06 & PRAMEF7 & 0.008655 \\
\hline NDC80 & 4.64E-06 & C1orf158 & 0.008699 \\
\hline TMEM145 & 4.70E-06 & TLX1 & 0.008853 \\
\hline TNNT2 & 4.91E-06 & TEDDM1 & 0.008955 \\
\hline GINS1 & 5.17E-06 & CBX2 & 0.009009 \\
\hline ORC1 & 5.23E-06 & JPH3 & 0.009072 \\
\hline BIRC5 & 5.35E-06 & TAC3 & 0.009123 \\
\hline LENEP & 5.64E-06 & EXO1 & 0.009224 \\
\hline TTK & 5.98E-06 & EDIL3 & 0.009264 \\
\hline MESP2 & $6.08 \mathrm{E}-06$ & CSMD2 & 0.009306 \\
\hline FBXO43 & 6.63E-06 & PZP & 0.009467 \\
\hline S100A1 & 7.68E-06 & BPIFB6 & 0.009526 \\
\hline ASPM & 7.99E-06 & RIPPLY2 & 0.009682 \\
\hline PBK & 8.56E-06 & TMEM190 & 0.009709 \\
\hline WDR62 & 8.64E-06 & OR12D2 & 0.00982 \\
\hline CCDC78 & 8.89E-06 & TNNI3 & 0.010009 \\
\hline РTP4A3 & $9.15 E-06$ & MRAP2 & 0.010031 \\
\hline FBXL16 & $9.25 \mathrm{E}-06$ & GUCY2D & 0.010194 \\
\hline
\end{tabular}

Table S1 (continued)
Table S1 (continued)

\begin{tabular}{|c|c|c|c|}
\hline geneName & pvalue & geneName & pvalue \\
\hline GRIK2 & $1.05 E-05$ & PAX2 & 0.010196 \\
\hline LRAT & $1.05 E-05$ & PDE1C & 0.010331 \\
\hline AGBL4 & $1.07 \mathrm{E}-05$ & IL11 & 0.010425 \\
\hline DNASE1L2 & $1.11 \mathrm{E}-05$ & MYBPHL & 0.010445 \\
\hline PRR11 & $1.14 \mathrm{E}-05$ & CETP & 0.010487 \\
\hline CR1 & $1.14 \mathrm{E}-05$ & FAM183A & 0.010659 \\
\hline SLC25A47 & 1.16E-05 & TRAIP & 0.010926 \\
\hline C5orf34 & $1.34 \mathrm{E}-05$ & LHFPL4 & 0.010995 \\
\hline MAEL & $1.36 \mathrm{E}-05$ & FUT2 & 0.011094 \\
\hline DIRAS3 & $1.41 \mathrm{E}-05$ & MSLN & 0.011203 \\
\hline C16orf89 & 1.59E-05 & CD5L & 0.01121 \\
\hline RDM1 & 1.60E-05 & ADAMTS13 & 0.011247 \\
\hline PITX2 & $1.70 \mathrm{E}-05$ & ТТС39A & 0.011854 \\
\hline TPPP2 & $1.80 \mathrm{E}-05$ & DCC & 0.01196 \\
\hline CLSPN & $1.81 \mathrm{E}-05$ & MELK & 0.012074 \\
\hline AC024361.1 & $1.94 \mathrm{E}-05$ & ECM1 & 0.012366 \\
\hline STRIP2 & 2.06E-05 & CHGA & 0.01239 \\
\hline SLC30A2 & 2.07E-05 & PTHLH & 0.012456 \\
\hline C20orf144 & 2.24E-05 & OIT3 & 0.012494 \\
\hline TRAM1L1 & 2.37E-05 & ANGPTL7 & 0.012827 \\
\hline MXD3 & 2.62E-05 & C21orf62 & 0.012866 \\
\hline TOP2A & 2.71E-05 & CNTNAP4 & 0.012944 \\
\hline LPA & 3.01E-05 & UBD & 0.01296 \\
\hline KIF14 & $3.14 \mathrm{E}-05$ & CCNB2 & 0.013309 \\
\hline EPS8L3 & 3.30E-05 & SPINK4 & 0.01402 \\
\hline MCM10 & 3.86E-05 & EGR2 & 0.014201 \\
\hline MRO & 3.93E-05 & RASGEF1A & 0.014375 \\
\hline RND3 & $4.25 \mathrm{E}-05$ & VSIG10L & 0.014389 \\
\hline ZIC2 & 4.65E-05 & TRIM16L & 0.014399 \\
\hline FGF4 & 4.67E-05 & DMBT1 & 0.014437 \\
\hline HHIPL2 & 4.83E-05 & $\mathrm{EZH} 2$ & 0.014555 \\
\hline KIFC1 & 4.85E-05 & CCDC28B & 0.014596 \\
\hline FANCI & 4.94E-05 & TGM4 & 0.014599 \\
\hline SKA1 & 4.98E-05 & SIGLEC7 & 0.014646 \\
\hline
\end{tabular}

Table S1 (continued) 
Table S1 (continued)

\begin{tabular}{|c|c|c|c|}
\hline geneName & pvalue & geneName & pvalue \\
\hline CCNE2 & 5.38E-05 & HGF & 0.014699 \\
\hline NGFR & 5.98E-05 & CFP & 0.014755 \\
\hline FAM83D & 5.98E-05 & NTSR2 & 0.015076 \\
\hline C19orf67 & 6.33E-05 & FBP1 & 0.015648 \\
\hline ANGPTL6 & $6.45 \mathrm{E}-05$ & CLEC1B & 0.015697 \\
\hline PRC1 & $6.78 \mathrm{E}-05$ & DNTT & 0.015697 \\
\hline $\mathrm{C} 7$ & 6.95E-05 & DRGX & 0.015788 \\
\hline SLC44A5 & 7.01E-05 & SEZ6L2 & 0.015861 \\
\hline UBE2C & 7.10E-05 & PAQR4 & 0.015928 \\
\hline TRIM71 & $7.18 \mathrm{E}-05$ & RASD2 & 0.015981 \\
\hline LRRN3 & $7.28 \mathrm{E}-05$ & ZNF676 & 0.016049 \\
\hline POU3F2 & 7.71E-05 & PADI3 & 0.016076 \\
\hline PRAMEF4 & 8.06E-05 & FANCB & 0.016291 \\
\hline RGS20 & 8.29E-05 & SPATC1L & 0.016313 \\
\hline KIF18B & 8.36E-05 & $\mathrm{COCH}$ & 0.01653 \\
\hline ADCY8 & 8.48E-05 & RGS9BP & 0.016607 \\
\hline CDCA2 & 0.000102 & DMP1 & 0.016619 \\
\hline DLL3 & 0.000104 & SLC6A18 & 0.016933 \\
\hline AADAT & 0.000104 & ADIPOQ & 0.017094 \\
\hline CDC6 & 0.000106 & DKK1 & 0.017225 \\
\hline $\mathrm{ADH} 4$ & 0.000108 & PLAC8 & 0.017327 \\
\hline CDCA8 & 0.000109 & PAGE4 & 0.017676 \\
\hline DEPDC1 & 0.000111 & WDHD1 & 0.017731 \\
\hline CDKN2C & 0.000116 & SAPCD2 & 0.017842 \\
\hline MND1 & 0.00012 & NUSAP1 & 0.017873 \\
\hline CHRNB2 & 0.000128 & PCDHA1 & 0.018016 \\
\hline DYDC2 & 0.000139 & BCAN & 0.018236 \\
\hline MUC12 & 0.000144 & SPHK1 & 0.01825 \\
\hline GPRIN1 & 0.000144 & CSN3 & 0.018537 \\
\hline IGSF3 & 0.000149 & $\mathrm{KCNH} 2$ & 0.018574 \\
\hline MSX1 & 0.00015 & RTKN2 & 0.018576 \\
\hline OR2B6 & 0.000153 & SCN1A & 0.018671 \\
\hline LCAT & 0.000165 & MCOLN3 & 0.018741 \\
\hline TBC1D26 & 0.000166 & ASF1B & 0.018794 \\
\hline
\end{tabular}

Table S1 (continued)
Table S1 (continued)

\begin{tabular}{|c|c|c|c|}
\hline geneName & pvalue & geneName & pvalue \\
\hline SP5 & 0.00017 & TEX19 & 0.019257 \\
\hline BLM & 0.000206 & TNFRSF9 & 0.019682 \\
\hline TNNC1 & 0.000207 & MAFA & 0.020213 \\
\hline FCN3 & 0.000211 & AQP10 & 0.020458 \\
\hline MYOM2 & 0.000211 & KCTD8 & 0.020701 \\
\hline ILDR2 & 0.000212 & NPY1R & 0.020904 \\
\hline FOS & 0.000213 & SH3GL3 & 0.021176 \\
\hline WNT3A & 0.000222 & CSTL1 & 0.021369 \\
\hline IL17D & 0.000236 & $\mathrm{KCNH} 4$ & 0.021465 \\
\hline MYBL2 & 0.00024 & DLX5 & 0.021492 \\
\hline INSRR & 0.000242 & TSPAN5 & 0.021552 \\
\hline GDAP1L1 & 0.000248 & UGT2B11 & 0.021569 \\
\hline TRIM16 & 0.000248 & CELF3 & 0.021576 \\
\hline SFN & 0.00025 & CXCL12 & 0.021793 \\
\hline NEFL & 0.000272 & DYDC1 & 0.022052 \\
\hline RAD54L & 0.000276 & KEL & 0.022118 \\
\hline PLK5 & 0.000279 & ADRA2C & 0.022513 \\
\hline FOXD2 & 0.00028 & RPS6KL1 & 0.022855 \\
\hline AHNAK2 & 0.000283 & ASPG & 0.022965 \\
\hline WDR87 & 0.000308 & LCN2 & 0.022966 \\
\hline CYP11B2 & 0.000309 & PDZK1IP1 & 0.02298 \\
\hline CUZD1 & 0.000316 & UTS2R & 0.023074 \\
\hline SYT5 & 0.00032 & C6orf223 & 0.023328 \\
\hline CRLF1 & 0.000355 & PSMA8 & 0.023559 \\
\hline EFNA3 & 0.000365 & TMEM266 & 0.023876 \\
\hline GNGT1 & 0.000383 & RBPJL & 0.023947 \\
\hline $\mathrm{AMH}$ & 0.000393 & KCNN1 & 0.024105 \\
\hline CDRT1 & 0.000409 & PHYHIPL & 0.024326 \\
\hline IL1RAP & 0.000409 & GJC1 & 0.024525 \\
\hline FGF20 & 0.000426 & RNF224 & 0.024879 \\
\hline FLNC & 0.000426 & CLLU1 & 0.024925 \\
\hline CHAF1B & 0.000432 & REC114 & 0.025168 \\
\hline DIO2 & 0.000439 & BUB1B & 0.025173 \\
\hline HIST1H3H & 0.000445 & TMEM26 & 0.025593 \\
\hline
\end{tabular}

Table S1 (continued) 
Table S1 (continued)

\begin{tabular}{|c|c|c|c|}
\hline geneName & pvalue & geneName & pvalue \\
\hline PRAMEF15 & 0.000447 & CCNO & 0.026383 \\
\hline CERS1 & 0.000453 & SPTA1 & 0.026717 \\
\hline SPC25 & 0.000472 & KIRREL2 & 0.026986 \\
\hline RXFP4 & 0.000495 & ARHGAP11A & 0.02749 \\
\hline CENPU & 0.000499 & FOXN4 & 0.028642 \\
\hline HIST1H2AM & 0.0005 & DDIT4L & 0.028701 \\
\hline CDC20 & 0.000542 & CLEC4M & 0.029083 \\
\hline CPLX2 & 0.00058 & MT1M & 0.029124 \\
\hline MAPT & 0.000582 & GABRG2 & 0.029433 \\
\hline TMEM61 & 0.000583 & SLC10A4 & 0.029756 \\
\hline PRR19 & 0.000585 & ADAM18 & 0.0299 \\
\hline TICRR & 0.000611 & LHX8 & 0.029963 \\
\hline BHLHA9 & 0.000613 & TMEM130 & 0.029969 \\
\hline PRAMEF11 & 0.000676 & HTR3B & 0.030061 \\
\hline MLANA & 0.000711 & TSLP & 0.030157 \\
\hline RHBG & 0.000722 & FXYD3 & 0.030387 \\
\hline MT1G & 0.000731 & GFY & 0.030621 \\
\hline MYH7B & 0.000743 & TWIST2 & 0.030742 \\
\hline AP1M2 & 0.000771 & ARX & 0.031148 \\
\hline NRCAM & 0.000817 & CDCA3 & 0.031234 \\
\hline MT1E & 0.000818 & TMEM178B & 0.031289 \\
\hline FAM24B & 0.000826 & HIST1H2BL & 0.031348 \\
\hline LEF1 & 0.000833 & HELLS & 0.031363 \\
\hline KIF2C & 0.000862 & DLX2 & 0.031769 \\
\hline SYN3 & 0.000866 & SOHLH1 & 0.031942 \\
\hline STIL & 0.000877 & VASH2 & 0.03258 \\
\hline SPARCL1 & 0.000891 & $\mathrm{HIST} 1 \mathrm{H} 4 \mathrm{H}$ & 0.033016 \\
\hline NKPD1 & 0.000891 & $\mathrm{CDH} 22$ & 0.03303 \\
\hline DMKN & 0.000898 & MCCD1 & 0.033099 \\
\hline CPEB3 & 0.000902 & GABRA2 & 0.033139 \\
\hline GPM6A & 0.000935 & PCSK1N & 0.03334 \\
\hline MYH13 & 0.000943 & AKR1B15 & 0.033566 \\
\hline SKA3 & 0.000949 & HJURP & 0.033946 \\
\hline ZIC5 & 0.000957 & C1orf61 & 0.034063 \\
\hline
\end{tabular}

Table S1 (continued)
Table S1 (continued)

\begin{tabular}{|c|c|c|c|}
\hline geneName & pvalue & geneName & pvalue \\
\hline RRM2 & 0.000964 & PXDNL & 0.034163 \\
\hline CCDC185 & 0.000975 & SCNN1G & 0.034168 \\
\hline CCNA2 & 0.000989 & OLFML2B & 0.034288 \\
\hline PTGS2 & 0.001067 & COMP & 0.034717 \\
\hline LILRA5 & 0.001077 & RBFOX1 & 0.034837 \\
\hline HIST1H4E & 0.001079 & $\mathrm{ERC} 2$ & 0.034892 \\
\hline CD24 & 0.001083 & CYP17A1 & 0.035361 \\
\hline DNAH3 & 0.001094 & COL7A1 & 0.035713 \\
\hline EXTL1 & 0.001175 & $\mathrm{MSH} 4$ & 0.035842 \\
\hline DCAF12L2 & 0.001198 & SCUBE1 & 0.036087 \\
\hline CACNA1B & 0.0012 & TUBAL3 & 0.036221 \\
\hline CELSR3 & 0.001218 & THY1 & 0.036838 \\
\hline FGF19 & 0.001243 & GPR19 & 0.036988 \\
\hline FPR2 & 0.00126 & KIF11 & 0.037047 \\
\hline $\mathrm{CDH} 24$ & 0.001268 & CLLU1OS & 0.03705 \\
\hline PRRX1 & 0.001304 & BAIAP2L2 & 0.0376 \\
\hline $\mathrm{BCO} 2$ & 0.00134 & TRIM17 & 0.038129 \\
\hline RIMS2 & 0.00136 & DRD4 & 0.038255 \\
\hline RGSL1 & 0.001462 & PTGFR & 0.038389 \\
\hline NKX1-2 & 0.001503 & FTHL17 & 0.038397 \\
\hline RNF157 & 0.001511 & FERMT1 & 0.038808 \\
\hline UNC5D & 0.001567 & HIST1H2AI & 0.038906 \\
\hline TCF24 & 0.001626 & IGFL2 & 0.039086 \\
\hline CRYBA4 & 0.001674 & NCAPG & 0.039138 \\
\hline CDK1 & 0.001683 & NKX3-2 & 0.039567 \\
\hline ATP4A & 0.001695 & PHEX & 0.039696 \\
\hline PRAMEF2 & 0.001698 & TACC3 & 0.039811 \\
\hline PADI4 & 0.001727 & HNRNPCL3 & 0.039879 \\
\hline MAMSTR & 0.001798 & $\mathrm{CRH}$ & 0.039978 \\
\hline BDKRB1 & 0.0018 & EDARADD & 0.040143 \\
\hline C1QTNF3 & 0.001806 & CTNND2 & 0.040363 \\
\hline SLC7A10 & 0.001818 & KRT12 & 0.0405 \\
\hline AKR1B10 & 0.00182 & GPRC6A & 0.040554 \\
\hline CDT1 & 0.001827 & SLC6A7 & 0.04062 \\
\hline
\end{tabular}

Table S1 (continued) 
Table S1 (continued)

\begin{tabular}{|c|c|c|c|}
\hline geneName & pvalue & geneName & pvalue \\
\hline SORCS3 & 0.001905 & CAGE1 & 0.04086 \\
\hline CENPF & 0.001933 & AMBN & 0.041144 \\
\hline STMN1 & 0.001953 & ZNF729 & 0.041209 \\
\hline CAPN8 & 0.00207 & STOML3 & 0.041328 \\
\hline KCNA1 & 0.002138 & PPP1R1B & 0.041339 \\
\hline FANCD2 & 0.002144 & FGF8 & 0.041766 \\
\hline KIF23 & 0.002221 & COLCA2 & 0.041779 \\
\hline STK39 & 0.002222 & SLC01B3 & 0.041793 \\
\hline TRIM63 & 0.002265 & EEF1A2 & 0.042188 \\
\hline UPK1A & 0.002272 & SFRP4 & 0.042195 \\
\hline GFAP & 0.002313 & MAGEB1 & 0.042222 \\
\hline ORC6 & 0.002334 & CST2 & 0.042229 \\
\hline ANO2 & 0.002354 & ATP6V0D2 & 0.042445 \\
\hline RNF151 & 0.002371 & MAGEB16 & 0.042488 \\
\hline CDH12 & 0.0024 & CCDC155 & 0.043075 \\
\hline RBM24 & 0.002474 & SLCO1C1 & 0.043108 \\
\hline CDC7 & 0.002552 & PLVAP & 0.043201 \\
\hline GJA3 & 0.002599 & PYDC1 & 0.04323 \\
\hline ZIC4 & 0.002637 & PAGE1 & 0.043298 \\
\hline
\end{tabular}

Table S1 (continued)
Table S1 (continued)

\begin{tabular}{|c|c|c|c|}
\hline geneName & pvalue & geneName & pvalue \\
\hline DMRTB1 & 0.002856 & PPP1R14C & 0.04356 \\
\hline ZWINT & 0.002924 & RHBDL3 & 0.043841 \\
\hline CRIP3 & 0.002929 & ARID3A & 0.04389 \\
\hline EGF & 0.002939 & KIF19 & 0.044518 \\
\hline PRR36 & 0.002949 & MT1B & 0.044538 \\
\hline DCAF4L1 & 0.00295 & SDR16C5 & 0.044821 \\
\hline CPA6 & 0.003043 & SLC30A8 & 0.044885 \\
\hline SLC5A11 & 0.003067 & SYT2 & 0.045084 \\
\hline FHAD1 & 0.003071 & NPHS1 & 0.045219 \\
\hline CCDC13 & 0.003075 & PSAPL1 & 0.045438 \\
\hline CCL25 & 0.003123 & HIST3H2BB & 0.045642 \\
\hline MT1F & 0.003136 & KCNJ6 & 0.045655 \\
\hline RNFT2 & 0.003155 & CCBE1 & 0.04567 \\
\hline MOS & 0.003209 & C1QL1 & 0.046086 \\
\hline FITM1 & 0.00321 & FBXW10 & 0.046112 \\
\hline KCNJ5 & 0.003402 & QRFPR & 0.046277 \\
\hline TSPO2 & 0.003711 & SLC12A1 & 0.047138 \\
\hline STMND1 & 0.003717 & TMEM155 & 0.047734 \\
\hline GLP2R & 0.00375 & KPNA7 & 0.047942 \\
\hline TLL2 & 0.003847 & IGFALS & 0.048685 \\
\hline ARFGEF3 & 0.003936 & ESR1 & 0.049811 \\
\hline
\end{tabular}

Table S2 Wilcoxon rank-sum results

\begin{tabular}{llllll}
\hline gene & conMean & treatMean & logFC & pValue & fdr \\
\hline PITX2 & 0.014548 & 0.114562 & 2.977216 & 0.001589 & 0.001679 \\
RBM24 & 0.271788 & 1.516507 & 2.4802 & $1.50 \mathrm{E}-16$ & $2.69 \mathrm{E}-16$ \\
UBE2C & 0.020923 & 8.417896 & 8.652209 & $1.02 \mathrm{E}-21$ & $2.67 \mathrm{E}-21$ \\
OLFML2B & 0.098781 & 2.417167 & 4.612942 & $2.35 \mathrm{E}-27$ & $2.15 \mathrm{E}-26$ \\
ASB16 & 0.272465 & 0.641053 & 1.234375 & $4.44 \mathrm{E}-23$ & $1.35 \mathrm{E}-22$ \\
CCNE1 & 0.010827 & 2.292889 & 7.726339 & $4.44 \mathrm{E}-25$ & $1.79 \mathrm{E}-24$ \\
SYT5 & 0.042541 & 0.118585 & 1.478985 & $1.22 \mathrm{E}-08$ & $1.56 \mathrm{E}-08$ \\
GINS1 & 0.178909 & 1.851394 & 3.371313 & $3.95 \mathrm{E}-25$ & $1.61 \mathrm{E}-24$ \\
CDKN2C & 0.52573 & 4.201133 & 2.998385 & $3.01 \mathrm{E}-28$ & $5.90 \mathrm{E}-27$ \\
AMH & 0.10028 & 0.326345 & 1.702369 & $6.50 \mathrm{E}-08$ & $7.97 \mathrm{E}-08$ \\
\hline
\end{tabular}

Table S2 (continued) 
Table S2 (continued)

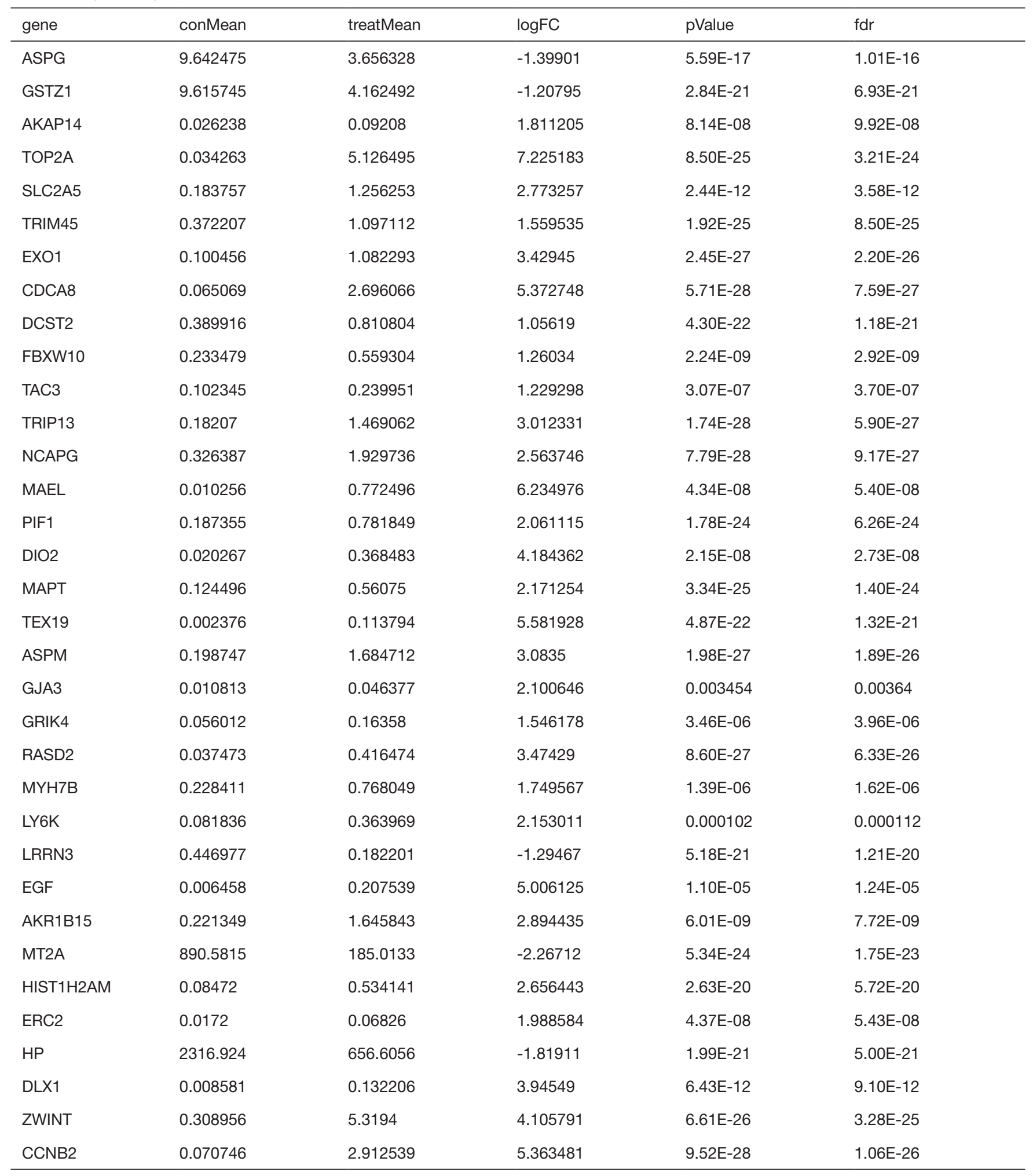

Table S2 (continued) 
Table S2 (continued)

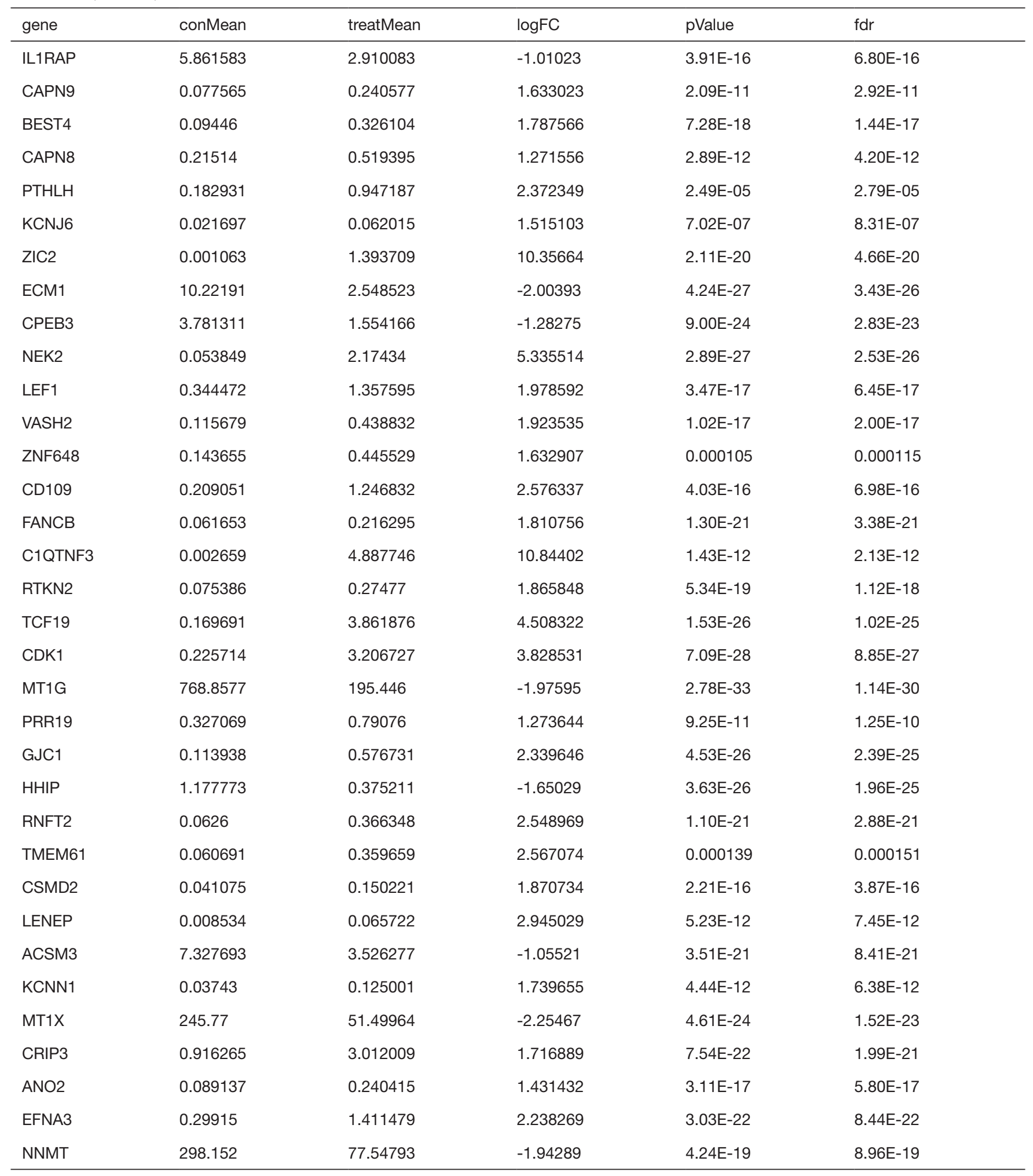

Table S2 (continued) 
Table S2 (continued)

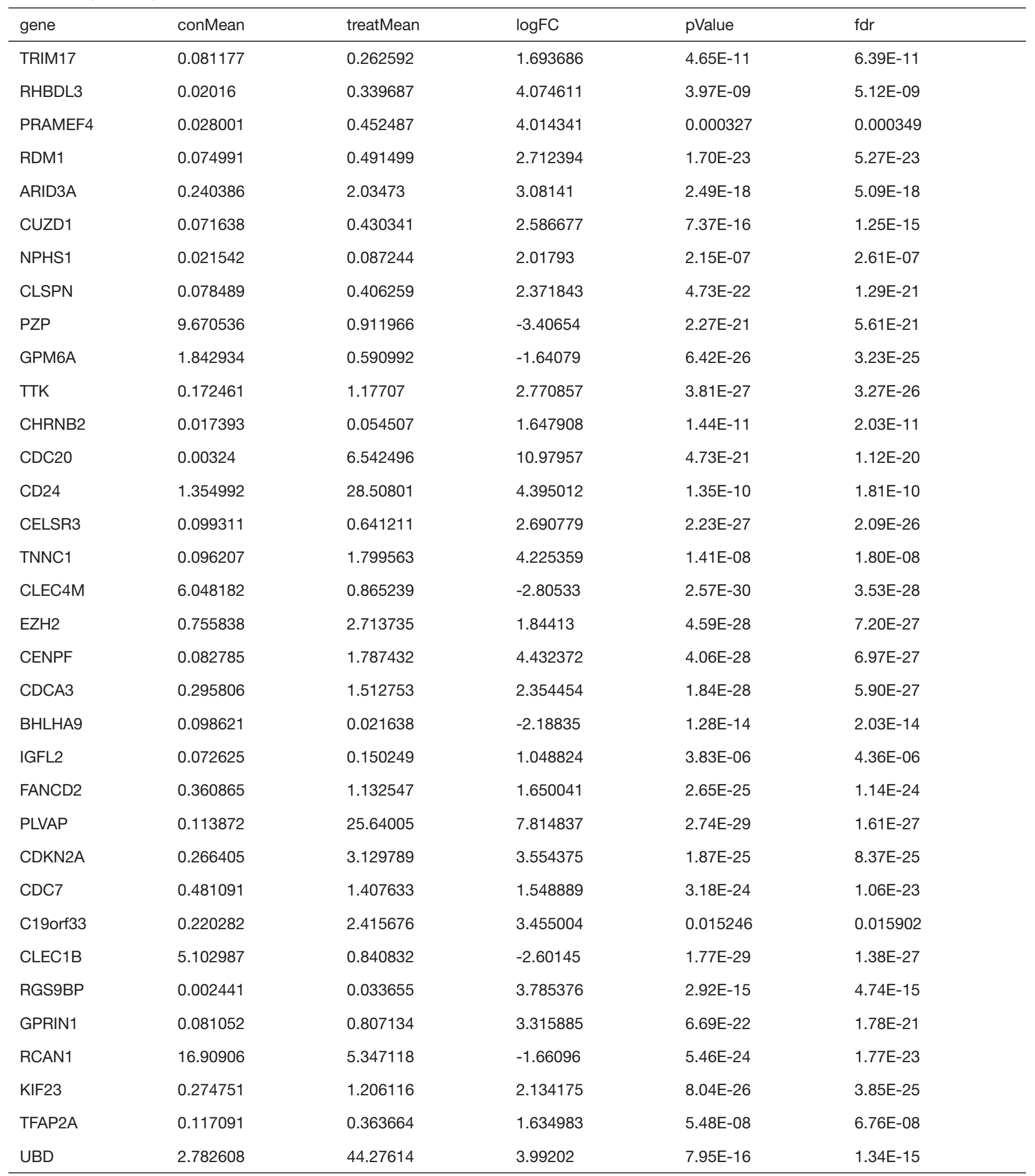

Table S2 (continued) 
Table S2 (continued)

\begin{tabular}{|c|c|c|c|c|c|}
\hline gene & conMean & treatMean & $\log F C$ & pValue & $\mathrm{fdr}$ \\
\hline DIRAS3 & 2.731089 & 0.872223 & -1.64671 & 2.04E-22 & 5.82E-22 \\
\hline NPY1R & 2.265229 & 1.038644 & -1.12496 & 1.64E-22 & $4.72 \mathrm{E}-22$ \\
\hline DNAJC6 & 0.139482 & 0.729746 & 2.387314 & 1.97E-21 & $4.98 \mathrm{E}-21$ \\
\hline RGS20 & 0.021651 & 0.095341 & 2.138638 & $1.57 \mathrm{E}-12$ & $2.32 \mathrm{E}-12$ \\
\hline FOXN4 & 0.166522 & 0.895339 & 2.426722 & 0.001048 & 0.001113 \\
\hline ORC1 & 0.122423 & 1.099514 & 3.166917 & $3.62 E-26$ & 1.96E-25 \\
\hline IQCD & 0.081773 & 0.514416 & 2.653235 & $5.48 \mathrm{E}-21$ & $1.28 \mathrm{E}-20$ \\
\hline E2F1 & 0.042362 & 5.598552 & 7.046154 & $2.62 E-23$ & 8.06E-23 \\
\hline KIF14 & 0.121035 & 0.683004 & 2.496475 & $5.88 \mathrm{E}-26$ & 3.03E-25 \\
\hline FHAD1 & 0.067709 & 0.184671 & 1.447543 & $1.15 \mathrm{E}-13$ & $1.80 \mathrm{E}-13$ \\
\hline FABP4 & 0.329511 & 6.321003 & 4.261756 & $3.49 \mathrm{E}-10$ & $4.64 \mathrm{E}-10$ \\
\hline EPS8L3 & 0.023725 & 3.821074 & 7.331422 & $1.93 \mathrm{E}-16$ & $3.41 \mathrm{E}-16$ \\
\hline DLX5 & 0.009925 & 0.220976 & 4.476685 & $3.86 \mathrm{E}-14$ & $6.08 \mathrm{E}-14$ \\
\hline CENPW & 0.257762 & 5.643826 & 4.452562 & 8.05E-28 & $9.21 \mathrm{E}-27$ \\
\hline CXCL12 & 21.69151 & 5.292733 & -2.03505 & $1.08 \mathrm{E}-24$ & $3.95 \mathrm{E}-24$ \\
\hline SKA1 & 0.010313 & 1.430236 & 7.115643 & $2.87 \mathrm{E}-28$ & $5.90 \mathrm{E}-27$ \\
\hline TMEM145 & 0.063502 & 0.428228 & 2.75351 & $1.00 \mathrm{E}-19$ & $2.15 \mathrm{E}-19$ \\
\hline OIP5 & 0.321466 & 1.607628 & 2.322194 & $6.58 \mathrm{E}-24$ & 2.10E-23 \\
\hline NRCAM & 0.150986 & 1.097458 & 2.86168 & 0.000107 & 0.000116 \\
\hline NGFR & 5.139406 & 2.249034 & -1.1923 & 8.26E-18 & $1.63 \mathrm{E}-17$ \\
\hline SLC6A9 & 0.262446 & 1.005621 & 1.937993 & $4.04 \mathrm{E}-15$ & $6.50 \mathrm{E}-15$ \\
\hline SERPINE1 & 82.85032 & 24.82337 & -1.73881 & $1.78 \mathrm{E}-11$ & $2.49 \mathrm{E}-11$ \\
\hline S100A1 & 0.628054 & 2.948731 & 2.231134 & 7.33E-12 & $1.03 \mathrm{E}-11$ \\
\hline MESP2 & 0.011331 & 0.579584 & 5.676711 & 2.87E-25 & $1.22 \mathrm{E}-24$ \\
\hline HPDL & 0.03376 & 0.272197 & 3.011271 & $1.75 \mathrm{E}-16$ & $3.11 \mathrm{E}-16$ \\
\hline
\end{tabular}

Table S2 (continued) 
Table S2 (continued)

\begin{tabular}{|c|c|c|c|c|c|}
\hline gene & conMean & treatMean & $\log F C$ & pValue & $\mathrm{fdr}$ \\
\hline SLC44A5 & 0.205607 & 0.840544 & 2.031431 & 0.005659 & 0.005933 \\
\hline FAM183A & 0.115749 & 0.390169 & 1.753102 & 4.93E-05 & $5.45 \mathrm{E}-05$ \\
\hline DRD4 & 0.200916 & 0.849174 & 2.079467 & $1.06 \mathrm{E}-14$ & $1.68 \mathrm{E}-14$ \\
\hline KIF11 & 0.267462 & 1.535667 & 2.52146 & $9.53 \mathrm{E}-26$ & 4.51E-25 \\
\hline TDGF1 & 0.285436 & 1.506102 & 2.39958 & 3.96E-05 & 4.39E-05 \\
\hline E2F2 & 0.047971 & 0.486718 & 3.342856 & $3.43 \mathrm{E}-25$ & $1.41 \mathrm{E}-24$ \\
\hline MNS1 & 0.358531 & 1.890552 & 2.398639 & $5.34 \mathrm{E}-14$ & 8.37E-14 \\
\hline SFRP4 & 0.183978 & 1.272288 & 2.789819 & $3.73 \mathrm{E}-14$ & $5.90 \mathrm{E}-14$ \\
\hline COMP & 0.116212 & 0.916884 & 2.97998 & $2.43 \mathrm{E}-05$ & 2.73E-05 \\
\hline AHNAK2 & 0.09837 & 0.371052 & 1.915331 & 0.031477 & 0.032502 \\
\hline FLVCR1 & 0.472587 & 2.082588 & 2.139724 & $2.14 \mathrm{E}-28$ & $5.90 \mathrm{E}-27$ \\
\hline CAP2 & 0.431424 & 5.887226 & 3.77041 & $6.49 \mathrm{E}-25$ & $2.52 E-24$ \\
\hline TRAIP & 0.196064 & 1.132998 & 2.53075 & $4.53 \mathrm{E}-28$ & $7.20 \mathrm{E}-27$ \\
\hline PLK4 & 0.214192 & 0.728801 & 1.766623 & 3.38E-25 & $1.41 \mathrm{E}-24$ \\
\hline C5orf34 & 0.165382 & 0.636554 & 1.944484 & $5.70 \mathrm{E}-28$ & $7.59 \mathrm{E}-27$ \\
\hline TK1 & 0.255001 & 12.09733 & 5.56804 & $1.02 \mathrm{E}-24$ & $3.75 \mathrm{E}-24$ \\
\hline OIT3 & 21.30992 & 3.413868 & -2.64205 & $7.53 \mathrm{E}-27$ & $5.72 \mathrm{E}-26$ \\
\hline ADAMTS13 & 4.936471 & 1.602208 & -1.62342 & 5.33E-28 & 7.57E-27 \\
\hline HIST1H4H & 0.102978 & 2.183295 & 4.406106 & 4.39E-18 & 8.86E-18 \\
\hline HIST2H4A & 0.005339 & 0.11679 & 4.451322 & $1.74 \mathrm{E}-16$ & $3.11 \mathrm{E}-16$ \\
\hline RNF151 & 0.02758 & 0.079913 & 1.534797 & $2.18 \mathrm{E}-08$ & 2.76E-08 \\
\hline MAMSTR & 0.144142 & 0.578966 & 2.005994 & $2.02 \mathrm{E}-24$ & $6.93 \mathrm{E}-24$ \\
\hline ATP6V0D2 & 0.088933 & 0.407899 & 2.197414 & 3.37E-12 & $4.88 \mathrm{E}-12$ \\
\hline FLNC & 0.023016 & 1.835133 & 6.3171 & 4.03E-06 & 4.58E-06 \\
\hline SLC10A4 & 0.042695 & 0.095917 & 1.167719 & $9.75 \mathrm{E}-07$ & $1.14 \mathrm{E}-06$ \\
\hline
\end{tabular}

Table S2 (continued) 
Table S2 (continued)

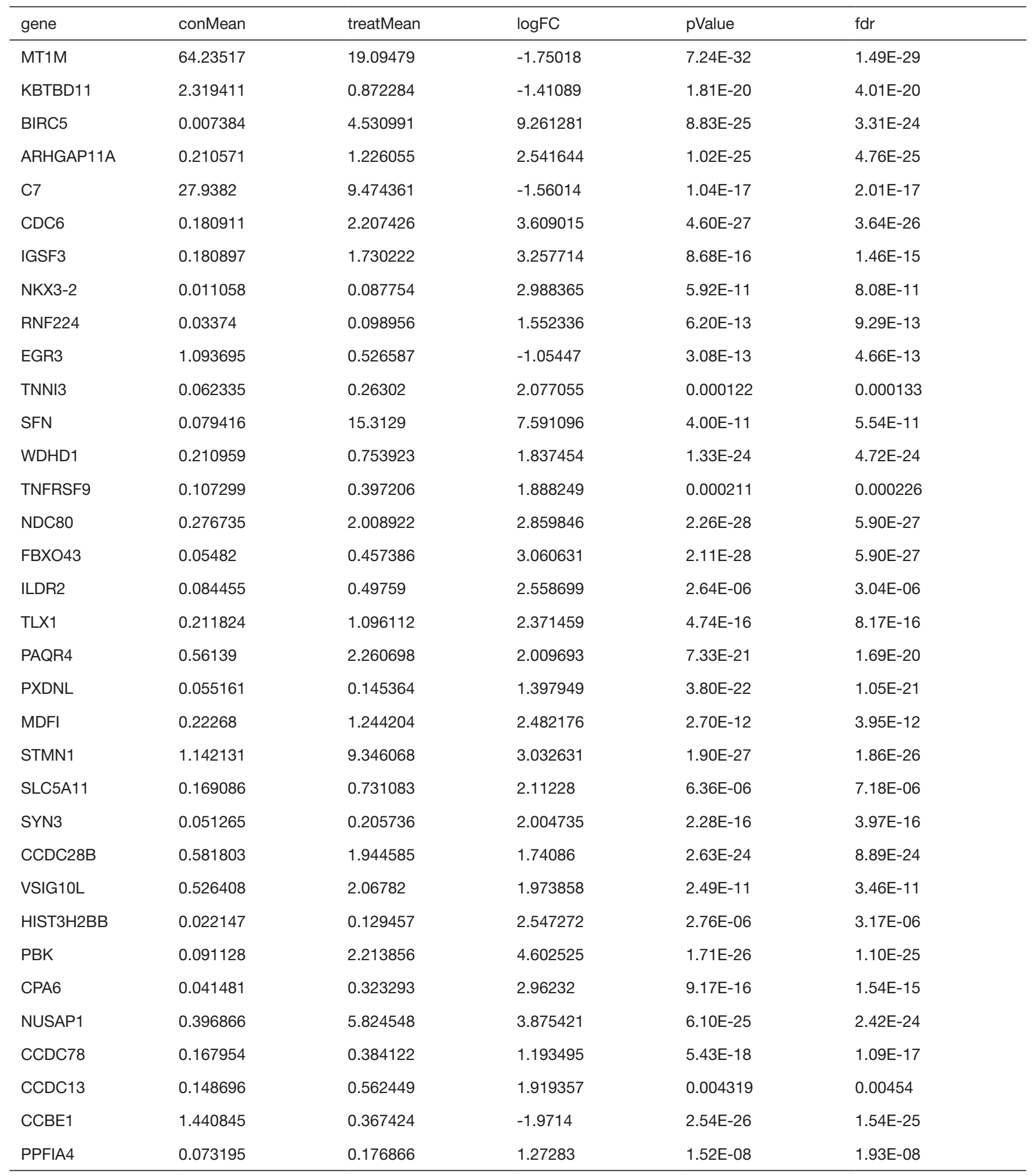

Table S2 (continued) 
Table S2 (continued)

\begin{tabular}{|c|c|c|c|c|c|}
\hline gene & conMean & treatMean & $\log F C$ & pValue & $\mathrm{fdr}$ \\
\hline FBXL16 & 0.083861 & 0.657118 & 2.970079 & 0.00014 & 0.000151 \\
\hline ESR1 & 2.41054 & 0.964269 & -1.32185 & $1.04 \mathrm{E}-22$ & $3.14 \mathrm{E}-22$ \\
\hline CDT1 & 0.040553 & 2.73458 & 6.07535 & $3.53 \mathrm{E}-26$ & $1.96 \mathrm{E}-25$ \\
\hline TACC3 & 0.725177 & 3.666278 & 2.337912 & $7.44 \mathrm{E}-26$ & $3.61 \mathrm{E}-25$ \\
\hline TRIM72 & 0.007662 & 0.062565 & 3.02949 & 8.27E-05 & 9.09E-05 \\
\hline STIL & 0.224356 & 0.793306 & 1.82209 & $2.79 \mathrm{E}-26$ & 1.64E-25 \\
\hline HELLS & 0.276158 & 0.910532 & 1.721215 & $3.84 \mathrm{E}-24$ & $1.28 \mathrm{E}-23$ \\
\hline HIST1H2AI & 0.013629 & 0.381497 & 4.806957 & $4.56 \mathrm{E}-17$ & 8.35E-17 \\
\hline NAT2 & 18.19904 & 3.44412 & -2.40165 & $1.20 \mathrm{E}-25$ & 5.56E-25 \\
\hline CBX2 & 0.154027 & 0.885284 & 2.522956 & $2.15 \mathrm{E}-24$ & 7.32E-24 \\
\hline RIMS2 & 0.031793 & 0.104287 & 1.713792 & 0.010853 & 0.011349 \\
\hline DNASE1L2 & 0.274263 & 0.599029 & 1.127067 & $5.26 \mathrm{E}-18$ & $1.06 \mathrm{E}-17$ \\
\hline TSPO2 & 0.122683 & 0.656604 & 2.420088 & $1.83 \mathrm{E}-15$ & $3.02 E-15$ \\
\hline HHIPL2 & 0.000103 & 1.102345 & 13.38249 & $8.41 \mathrm{E}-11$ & $1.14 \mathrm{E}-10$ \\
\hline CCNA2 & 0.193462 & 3.676458 & 4.248198 & $3.92 \mathrm{E}-27$ & $3.29 E-26$ \\
\hline CETP & 9.589907 & 2.364191 & -2.02017 & 2.59E-22 & 7.27E-22 \\
\hline WDR76 & 0.216672 & 1.370734 & 2.661362 & $1.89 \mathrm{E}-24$ & $6.61 \mathrm{E}-24$ \\
\hline ZNF296 & 0.189435 & 0.735477 & 1.956976 & 8.35E-18 & $1.64 \mathrm{E}-17$ \\
\hline MRO & 1.502704 & 0.60467 & -1.31334 & 6.67E-20 & $1.44 \mathrm{E}-19$ \\
\hline SHCBP1 & 0.141682 & 0.886207 & 2.644989 & $1.24 \mathrm{E}-25$ & $5.66 \mathrm{E}-25$ \\
\hline $\mathrm{COCH}$ & 0.136112 & 1.37987 & 3.341665 & $2.91 \mathrm{E}-13$ & $4.43 \mathrm{E}-13$ \\
\hline SCUBE1 & 0.336968 & 1.41675 & 2.071901 & 0.023346 & 0.024228 \\
\hline TRIM16 & 0.328119 & 2.510745 & 2.935824 & 4.96E-23 & 1.50E-22 \\
\hline AURKA & 0.227714 & 4.679457 & 4.361044 & $4.05 E-28$ & 6.97E-27 \\
\hline GDAP1L1 & 0.017947 & 0.0535 & 1.575766 & $3.14 \mathrm{E}-07$ & $3.78 \mathrm{E}-07$ \\
\hline
\end{tabular}

Table S2 (continued) 
Table S2 (continued)

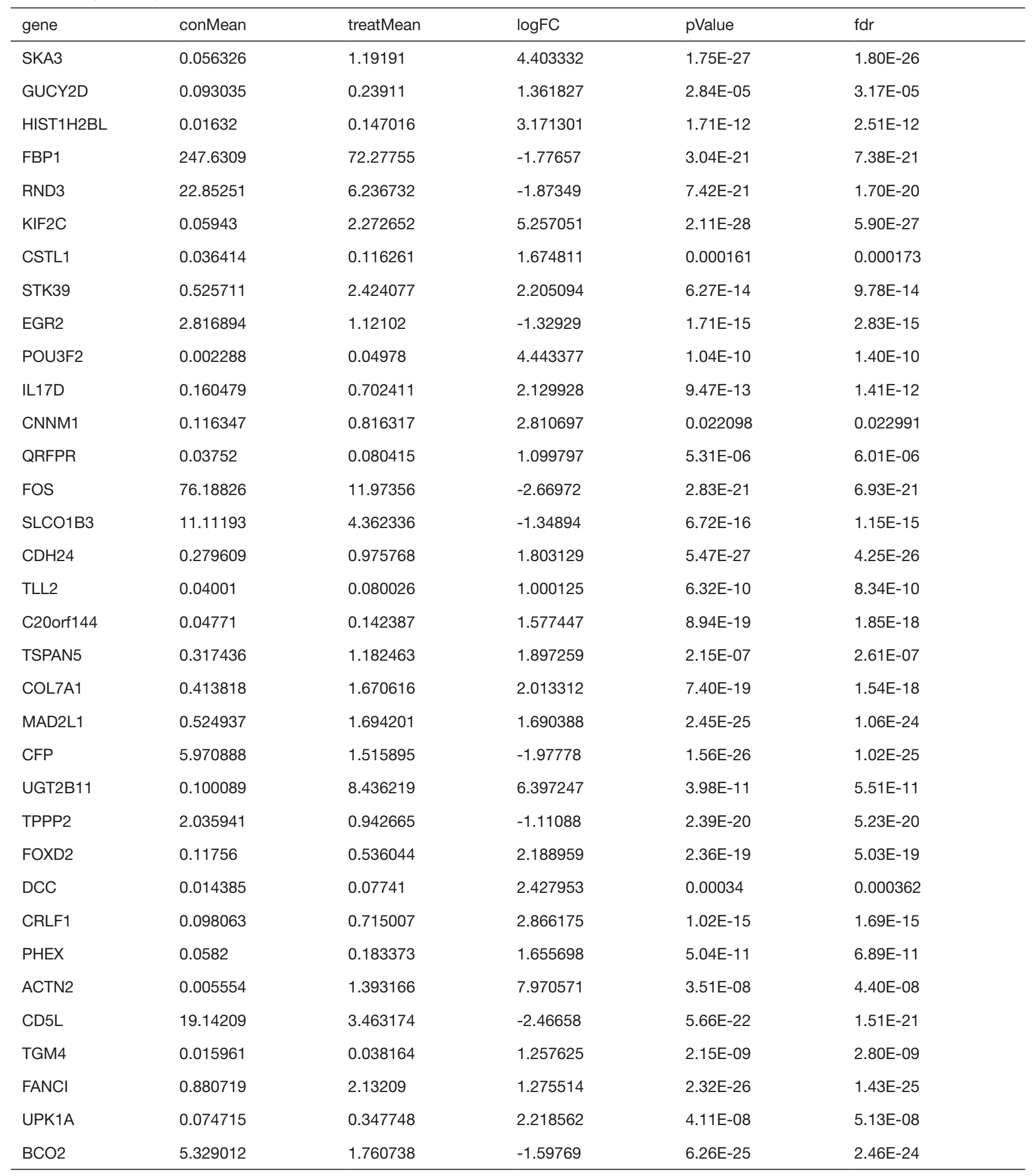

Table S2 (continued) 
Table S2 (continued)

\begin{tabular}{|c|c|c|c|c|c|}
\hline gene & conMean & treatMean & $\log F C$ & pValue & $\mathrm{fdr}$ \\
\hline GMNN & 0.548413 & 10.94823 & 4.319291 & $2.69 \mathrm{E}-28$ & $5.90 \mathrm{E}-27$ \\
\hline PRC1 & 0.329856 & 2.960605 & 3.165984 & $2.42 \mathrm{E}-28$ & $5.90 \mathrm{E}-27$ \\
\hline BCAN & 0.173971 & 0.702088 & 2.012807 & $2.02 \mathrm{E}-21$ & $5.04 \mathrm{E}-21$ \\
\hline SPARCL1 & 0.066112 & 26.77415 & 8.66171 & $2.74 \mathrm{E}-15$ & $4.46 \mathrm{E}-15$ \\
\hline WDR62 & 0.2259 & 0.849885 & 1.911585 & $1.21 \mathrm{E}-26$ & 8.34E-26 \\
\hline $\mathrm{KCNH} 4$ & 0.053671 & 0.175715 & 1.711018 & $9.59 \mathrm{E}-15$ & $1.53 \mathrm{E}-14$ \\
\hline KIF18B & 0.040063 & 1.188678 & 4.890942 & $7.58 \mathrm{E}-28$ & $9.17 \mathrm{E}-27$ \\
\hline ТTC39A & 0.248972 & 1.297075 & 2.381207 & $1.76 \mathrm{E}-17$ & 3.37E-17 \\
\hline GLP2R & 0.260314 & 0.114166 & -1.18912 & $9.50 \mathrm{E}-19$ & $1.96 \mathrm{E}-18$ \\
\hline TERT & 0 & 0.939635 & Inf & $9.15 \mathrm{E}-13$ & $1.37 \mathrm{E}-12$ \\
\hline LRAT & 1.474371 & 0.481465 & -1.6146 & $9.54 \mathrm{E}-25$ & $3.54 \mathrm{E}-24$ \\
\hline FERMT1 & 0.141558 & 0.863249 & 2.608387 & $1.75 \mathrm{E}-06$ & 2.02E-06 \\
\hline CCNE2 & 0.45629 & 0.954661 & 1.065039 & $1.61 \mathrm{E}-21$ & 4.13E-21 \\
\hline FITM1 & 3.128096 & 1.3153 & -1.24989 & 1.39E-20 & $3.11 \mathrm{E}-20$ \\
\hline SLC7A10 & 0.275615 & 0.984645 & 1.83695 & 7.61E-07 & 8.98E-07 \\
\hline ANGPTL6 & 7.103794 & 2.625283 & -1.43612 & $3.51 \mathrm{E}-29$ & $1.81 \mathrm{E}-27$ \\
\hline NKPD1 & 0.018546 & 0.044101 & 1.2497 & 1.74E-09 & $2.28 \mathrm{E}-09$ \\
\hline PKMYT1 & 0.355972 & 1.437709 & 2.013935 & $4.72 \mathrm{E}-28$ & $7.20 \mathrm{E}-27$ \\
\hline ЕСT2 & 0.400966 & 2.222478 & 2.470618 & 1.23E-24 & 4.41E-24 \\
\hline TRIM16L & 0.320882 & 4.18306 & 3.704443 & $2.21 \mathrm{E}-13$ & $3.39 \mathrm{E}-13$ \\
\hline BDKRB1 & 0.164212 & 0.39557 & 1.268376 & $5.68 \mathrm{E}-15$ & $9.10 \mathrm{E}-15$ \\
\hline SLC6A7 & 0.037054 & 0.094638 & 1.352795 & 4.36E-09 & 5.62E-09 \\
\hline CAGE1 & 0.046971 & 0.104224 & 1.149845 & $8.51 \mathrm{E}-07$ & $9.96 \mathrm{E}-07$ \\
\hline IQGAP3 & 0.230242 & 2.246248 & 3.286294 & $3.67 \mathrm{E}-26$ & $1.96 \mathrm{E}-25$ \\
\hline CCDC155 & 0.038716 & 0.093729 & 1.275566 & 0.001363 & 0.001443 \\
\hline
\end{tabular}

Table S2 (continued) 
Table S2 (continued)

\begin{tabular}{|c|c|c|c|c|c|}
\hline gene & conMean & treatMean & $\log F C$ & pValue & $\mathrm{fdr}$ \\
\hline CNTNAP4 & 0.076567 & 0.364232 & 2.250066 & 0.028635 & 0.029642 \\
\hline BLM & 0.164885 & 0.661975 & 2.005317 & $2.11 \mathrm{E}-22$ & $6.00 \mathrm{E}-22$ \\
\hline MND1 & 0.241854 & 1.541771 & 2.672377 & $7.63 \mathrm{E}-27$ & $5.72 \mathrm{E}-26$ \\
\hline NUF2 & 0.184491 & 1.831442 & 3.311358 & $1.74 \mathrm{E}-28$ & $5.90 \mathrm{E}-27$ \\
\hline ASF1B & 0.093824 & 3.079952 & 5.036814 & $3.14 \mathrm{E}-26$ & $1.82 E-25$ \\
\hline OR2B6 & 0.080812 & 0.330107 & 2.030299 & $2.38 \mathrm{E}-15$ & $3.91 \mathrm{E}-15$ \\
\hline HIST1H4E & 0.218822 & 0.737377 & 1.752645 & $2.46 \mathrm{E}-17$ & 4.67E-17 \\
\hline SLC26A6 & 0.739488 & 3.339663 & 2.175104 & $1.25 \mathrm{E}-29$ & 1.29E-27 \\
\hline DTL & 0.120552 & 1.880986 & 3.963764 & 3.35E-26 & $1.90 \mathrm{E}-25$ \\
\hline TRAM1L1 & 0.044896 & 0.433655 & 3.271898 & $2.68 \mathrm{E}-08$ & 3.36E-08 \\
\hline AADAT & 8.699237 & 2.427923 & -1.84117 & 7.44E-26 & $3.61 \mathrm{E}-25$ \\
\hline CHAF1B & 0.27502 & 1.271058 & 2.208421 & $6.03 \mathrm{E}-24$ & $1.94 \mathrm{E}-23$ \\
\hline CDC25A & 0.175584 & 0.919295 & 2.388369 & $3.35 \mathrm{E}-21$ & 8.07E-21 \\
\hline SPC25 & 0.176919 & 1.54862 & 3.129826 & 4.19E-27 & $3.43 E-26$ \\
\hline NTF3 & 1.871852 & 0.482896 & -1.95468 & $1.89 \mathrm{E}-27$ & $1.86 \mathrm{E}-26$ \\
\hline DYDC1 & 0.024611 & 0.082503 & 1.745123 & $5.23 \mathrm{E}-08$ & $6.47 \mathrm{E}-08$ \\
\hline C21orf62 & 0.158121 & 0.056999 & -1.47201 & 1.36E-20 & 3.07E-20 \\
\hline $\mathrm{ADH} 4$ & 511.6001 & 124.0821 & -2.04372 & 5.64E-22 & $1.51 \mathrm{E}-21$ \\
\hline PADI4 & 0.268474 & 0.125414 & -1.09809 & $3.70 \mathrm{E}-13$ & $5.59 \mathrm{E}-13$ \\
\hline GNAO1 & 2.292639 & 0.896881 & -1.35402 & $4.13 \mathrm{E}-17$ & 7.63E-17 \\
\hline RRM2 & 0.162038 & 4.357017 & 4.748936 & 4.70E-26 & 2.45E-25 \\
\hline COL24A1 & 0.089275 & 0.275864 & 1.627633 & $5.40 \mathrm{E}-12$ & $7.68 \mathrm{E}-12$ \\
\hline DCX & 0.003992 & 0.029109 & 2.86612 & 7.84E-07 & $9.22 \mathrm{E}-07$ \\
\hline PRDM9 & 0.006805 & 0.045411 & 2.738484 & 4.37E-10 & $5.79 \mathrm{E}-10$ \\
\hline LPA & 9.504567 & 3.082742 & -1.62441 & $2.38 \mathrm{E}-22$ & $6.72 \mathrm{E}-22$ \\
\hline
\end{tabular}

Table S2 (continued) 
Table S2 (continued)

\begin{tabular}{|c|c|c|c|c|c|}
\hline gene & conMean & treatMean & $\log F C$ & pValue & $\mathrm{fdr}$ \\
\hline CST2 & 0.058397 & 0.519969 & 3.154464 & 3.34E-07 & 3.99E-07 \\
\hline FUT2 & 0.066396 & 0.673373 & 3.342238 & $4.89 \mathrm{E}-16$ & 8.39E-16 \\
\hline EPHA2 & 10.73155 & 4.072777 & -1.39777 & $2.54 \mathrm{E}-13$ & $3.88 \mathrm{E}-13$ \\
\hline RPS6KL1 & 0.242699 & 0.818577 & 1.753951 & $5.05 E-21$ & 1.19E-20 \\
\hline THY1 & 0.530496 & 6.199475 & 3.546732 & 1.05E-26 & 7.32E-26 \\
\hline RXFP4 & 0.001164 & 0.045579 & 5.291249 & 5.97E-07 & 7.09E-07 \\
\hline KPNA7 & 0.146004 & 0.689252 & 2.239022 & $1.91 \mathrm{E}-13$ & $2.95 E-13$ \\
\hline DLL3 & 0.011792 & 0.06191 & 2.392375 & $1.60 \mathrm{E}-06$ & $1.86 \mathrm{E}-06$ \\
\hline PHYHIPL & 0.628596 & 2.246911 & 1.837737 & $5.85 \mathrm{E}-08$ & 7.20E-08 \\
\hline ADRA1A & 5.001141 & 1.346761 & -1.89276 & 1.94E-24 & $6.72 \mathrm{E}-24$ \\
\hline MYBPHL & 0.002037 & 0.247092 & 6.92225 & $1.64 \mathrm{E}-10$ & $2.20 \mathrm{E}-10$ \\
\hline EXTL1 & 0.023205 & 0.087017 & 1.906826 & $2.00 \mathrm{E}-13$ & $3.08 \mathrm{E}-13$ \\
\hline ORC6 & 0.291223 & 0.99971 & 1.779385 & $1.73 \mathrm{E}-26$ & 1.10E-25 \\
\hline MSX1 & 0.203942 & 0.939481 & 2.203703 & $8.45 E-24$ & $2.68 \mathrm{E}-23$ \\
\hline SP5 & 0.139479 & 3.448012 & 4.627647 & $4.05 \mathrm{E}-12$ & $5.83 \mathrm{E}-12$ \\
\hline
\end{tabular}


Table S3 Univariate Cox regression analysis for prognostic genes

\begin{tabular}{|c|c|c|c|c|}
\hline geneName & $\mathrm{HR}$ & HR.95L & HR.95H & pvalue \\
\hline CDCA8 & 1.161443 & 1.111036 & 1.214138 & $3.82 \mathrm{E}-11$ \\
\hline KIF2C & 1.149721 & 1.100378 & 1.201277 & $4.55 \mathrm{E}-10$ \\
\hline NCAPG & 1.241995 & 1.158143 & 1.331918 & $1.23 \mathrm{E}-09$ \\
\hline EZH2 & 1.268453 & 1.172108 & 1.372716 & 3.63E-09 \\
\hline TTK & 1.42605 & 1.266796 & 1.605326 & $4.25 \mathrm{E}-09$ \\
\hline HJURP & 1.240704 & 1.154514 & 1.333328 & 4.33E-09 \\
\hline NDC80 & 1.235031 & 1.150845 & 1.325375 & 4.62E-09 \\
\hline MCM10 & 1.668145 & 1.404275 & 1.981599 & 5.73E-09 \\
\hline CDCA2 & 1.66532 & 1.37961 & 2.010199 & $1.09 \mathrm{E}-07$ \\
\hline CBX2 & 1.272652 & 1.164052 & 1.391383 & 1.17E-07 \\
\hline GINS1 & 1.234745 & 1.141974 & 1.335052 & $1.21 \mathrm{E}-07$ \\
\hline PBK & 1.148177 & 1.089459 & 1.210059 & $2.48 \mathrm{E}-07$ \\
\hline SPC25 & 1.276769 & 1.163513 & 1.40105 & $2.53 \mathrm{E}-07$ \\
\hline ORC1 & 1.365331 & 1.211747 & 1.53838 & $3.15 \mathrm{E}-07$ \\
\hline CDCA3 & 1.312349 & 1.181954 & 1.457129 & 3.56E-07 \\
\hline RRM2 & 1.075061 & 1.04413 & 1.106909 & $1.18 \mathrm{E}-06$ \\
\hline ZWINT & 1.071171 & 1.041765 & 1.101406 & $1.29 \mathrm{E}-06$ \\
\hline IQGAP3 & 1.197815 & 1.113011 & 1.28908 & $1.45 \mathrm{E}-06$ \\
\hline MELK & 1.195048 & 1.111444 & 1.284941 & 1.47E-06 \\
\hline EXO1 & 1.370201 & 1.2042 & 1.559085 & $1.75 \mathrm{E}-06$ \\
\hline KIF18B & 1.243475 & 1.135927 & 1.361204 & $2.34 \mathrm{E}-06$ \\
\hline BUB1B & 1.223424 & 1.124856 & 1.330629 & $2.54 \mathrm{E}-06$ \\
\hline CENPL & 1.518228 & 1.275717 & 1.806839 & $2.57 \mathrm{E}-06$ \\
\hline GPRIN1 & 1.517847 & 1.275369 & 1.806427 & $2.62 \mathrm{E}-06$ \\
\hline KIFC1 & 1.090491 & 1.051699 & 1.130714 & 2.77E-06 \\
\hline NUF2 & 1.16044 & 1.090022 & 1.235408 & $3.18 \mathrm{E}-06$ \\
\hline
\end{tabular}

Table S3 (continued) 
Table S3 (continued)

\begin{tabular}{|c|c|c|c|c|}
\hline geneName & $\mathrm{HR}$ & HR.95L & HR.95H & pvalue \\
\hline AKR1B15 & 1.103243 & 1.057986 & 1.150437 & 4.28E-06 \\
\hline FAM83D & 1.114742 & 1.063797 & 1.168127 & 5.33E-06 \\
\hline ECT2 & 1.165551 & 1.090537 & 1.245725 & $6.38 \mathrm{E}-06$ \\
\hline UBE2T & 1.065509 & 1.036186 & 1.095661 & 8.33E-06 \\
\hline CLSPN & 1.782421 & 1.381119 & 2.300326 & 8.95E-06 \\
\hline EPS8L3 & 1.057431 & 1.031663 & 1.083843 & $9.14 \mathrm{E}-06$ \\
\hline ORC6 & 1.350585 & 1.181341 & 1.544077 & $1.08 \mathrm{E}-05$ \\
\hline CDC7 & 1.334669 & 1.171751 & 1.520239 & 1.39E-05 \\
\hline DEPDC1 & 1.330772 & 1.167418 & 1.516985 & $1.90 \mathrm{E}-05$ \\
\hline MYBL2 & 1.029306 & 1.015767 & 1.043025 & $1.91 \mathrm{E}-05$ \\
\hline TRIM16L & 1.04094 & 1.021875 & 1.06036 & $2.10 \mathrm{E}-05$ \\
\hline STMN1 & 1.034763 & 1.018426 & 1.051362 & 2.57E-05 \\
\hline FANCB & 3.487667 & 1.941422 & 6.265418 & 2.92E-05 \\
\hline TOP2A & 1.047175 & 1.024689 & 1.070154 & $3.15 \mathrm{E}-05$ \\
\hline SKA1 & 1.142587 & 1.072821 & 1.216889 & 3.37E-05 \\
\hline TRAIP & 1.336809 & 1.159584 & 1.541119 & 6.32E-05 \\
\hline $\mathrm{ZIC2}$ & 1.178347 & 1.08611 & 1.278417 & 7.94E-05 \\
\hline BIRC5 & 1.037407 & 1.018654 & 1.056505 & 7.95E-05 \\
\hline DSCC1 & 1.211351 & 1.100579 & 1.333271 & 8.90E-05 \\
\hline
\end{tabular}


Table S4 Risk score model for OS

\begin{tabular}{lccccc}
\hline geneName & coef & HR & HR.95L & HR.95H & pvalue \\
\hline CDCA8 & 0.192995 & 1.212877 & 0.941793 & 1.561987 & 0.13483 \\
AKR1B15 & 0.175446 & 1.191777 & 1.031897 & 0.016978 & 0.298674 \\
EZH2 & 0.141074 & 1.15151 & 0.882519 & 1.50249 & 1.372099 \\
EPS8L3 & 0.147772 & 1.159249 & 0.979418 & 1.284866 & 0.085769 \\
CBX2 & 0.071536 & 1.074157 & 0.898003 & 1.42093 & 0.433762 \\
TRIM16L & 0.183376 & 1.201267 & 1.015561 & 1.419626 & 0.03234 \\
FLVCR1 & 0.153859 & 1.166326 & 0.958221 & 0.124939 \\
GPRIN1 & 0.102045 & 1.107433 & 0.902035 & & 1.359601 \\
\hline
\end{tabular}

